Article

\title{
Dynamic Characteristics of Unsteady Aerodynamic Pressure on an Enclosed Housing for Sound Emission Alleviation Caused by a Passing High-Speed Train
}

\author{
Haiquan Jing ${ }^{1,2}{ }^{-}$, Xiaoyu Ji ${ }^{1,2}$, Xuhui He ${ }^{1,2, *}$, Shifeng Zhang ${ }^{3}$, Jichao Zhou ${ }^{3}$ and Haiyu Zhang ${ }^{3}$ \\ 1 School of Civil Engineering, Central South University, Changsha 410075, China; hq.jing@csu.edu.cn (H.J.); \\ xiaoyuj@csu.edu.cn (X.J.) \\ 2 National Engineering Laboratory for High-Speed Railway Construction, Changsha 410075, China \\ 3 China Railway Design Corporation, Tianjin 300308, China; zhangshifeng@crdc.com (S.Z.); \\ zhoujichao@crdc.com (J.Z.); zhanghaiyu@crdc.com (H.Z.) \\ * Correspondence: xuhuihe@csu.edu.cn
}

check for updates

Citation: Jing, H.; Ji, X.; He, X.; Zhang, S.; Zhou, J.; Zhang, H. Dynamic Characteristics of Unsteady Aerodynamic Pressure on an Enclosed Housing for Sound Emission Alleviation Caused by a Passing High-Speed Train. Appl. Sci. 2022, 12, 1545. https://doi.org/ 10.3390/app12031545

Academic Editor: Luís L. Ferrás

Received: 1 December 2021

Accepted: 19 January 2022

Published: 31 January 2022

Publisher's Note: MDPI stays neutral with regard to jurisdictional claims in published maps and institutional affiliations.

Copyright: (C) 2022 by the authors. Licensee MDPI, Basel, Switzerland. This article is an open access article distributed under the terms and conditions of the Creative Commons Attribution (CC BY) license (https:// creativecommons.org/licenses/by/ $4.0 /)$.

\begin{abstract}
Train speed is increasing due to the development of high-speed railway technology. However, high-speed trains generate more noise and discomfort for residents, enclosed housing for sound emission alleviation is needed to further reduce noise. Because these enclosed housings for sound emission alleviation restrain the air flow, strong and complicated aerodynamic pressures are generated inside the housing for sound emission alleviation when a train passes through at a high speed. This train-induced aerodynamic pressure, particularly its dynamic characteristics, is a key parameter in structural design. In the present study, the train-induced unsteady aerodynamic pressure in an enclosed housing for sound emission alleviation is simulated using the dynamic mesh method, and the dynamic characteristics of the aerodynamic pressure are investigated. The simulation results show that when the train is running in the enclosed housing for sound emission alleviation, the unsteady aerodynamic pressure is complicated and aperiodic, and after the train leaves the housing for sound emission alleviation, the aerodynamic pressure reverts to periodic decay curves. Two new terms, the duration of the extreme aerodynamic pressure and the pressure change rate, are proposed to evaluate the dynamic characteristics when the train passes through the barrier. The dominant frequency and decay rate are adopted to express the dynamic characteristics after the train exits. When the train runs in the enclosed housing for sound emission alleviation, the longest durations of the positive and negative extreme aerodynamic pressures are in the middle section, and the maximum change rate of aerodynamic pressure occurs at the entrance area. After the train exits the housing for sound emission alleviation, the pressure amplitude at the central region is always higher than those close to the entrance/exit. The dominant frequency of the aerodynamic pressure is identified and explained using wave propagation theory, the decay rate of the aerodynamic pressure at all sections is close.
\end{abstract}

Keywords: high-speed train; enclosed housing for sound emission alleviation; pressure wave; unsteady aerodynamic pressure; load patterns

\section{Introduction}

In recent decades, the vigorous development of high-speed railway technology has promoted an increase in train speed. When the train runs at high speed, it generates more vibrational and aerodynamic noise and discomforts the residents living close to the railway lines. To improve residential comfort, various housings for sound emission alleviation have been invented and installed on high-speed railway lines.

Traditional housings for sound emission alleviation are mainly vertical or curved open-style barriers. They are simple, easy to install and cost-effective structures. However, when high-speed trains pass through residential areas or villages, the noise reduction effectiveness of these traditional housings for sound emission alleviation is insufficient. In 
recent years, enclosed housings for sound emission alleviation have been proposed and are becoming increasingly popular because of their good noise reduction performance.

However, because the housings for sound emission alleviation restrain the air flow, when a train passes through at a high speed, strong and complicated aerodynamic pressures are generated in the housing for sound emission alleviation. The aerodynamic pressure can cause structural failure. For instance, housings for sound emission alleviation installed on the Cologne-Frankfurt line in Germany were damaged due to train-induced transient pressures in 2003 [1]. Therefore, to ensure the operational safety of railway lines, the transient pressure on housing for sound emission alleviation caused by a running train has been a key factor for the structural design of housing for sound emission alleviation.

Many researchers have investigated the transient pressure on traditional housing for sound emission alleviation caused by running trains. Baker et al. [2] conducted an experiment on a moving model train rig using a $1 / 25$ scale moving model device and measured the transient wind loads on the housing for sound emission alleviation, bridges, station canopies and trestle platforms caused by three different shapes of train models with different nose types. Lü et al. [3] and Xiong et al. [4] carried out field measurements and investigated the influence of the train speed, distances between the train and housing for sound emission alleviation, train types, and train marshaling length on the aerodynamic characteristics of the train-induced aerodynamic pressure on the housing for sound emission alleviation in the Datong-Xi'an and Beijing-Shanghai high-speed railway lines. They found that higher train speed and shorter distance increase the wind load acting on the housing for sound emission alleviation, the wind load becomes more sensitive to train speed when the distance is shorter, the time intervals of the peak-to-peak pressure on the housing for sound emission alleviation gradually decrease when the train speed increases, and the peak-to-peak pressure on the inner surface of the housing for sound emission alleviation becomes lower at higher monitoring points, while that on the outer surface becomes higher. Soper et al. [5] also conducted a series of field experiments to assess the pressure loads acting on housing for sound emission alleviation. They found that the train type has a great influence on the pressure fluctuations acting on the housing for sound emission alleviation and noted that the wind load caused different types of traffic moving on the railway should be taken into consideration.

For enclosed housing for sound emission alleviation, studies on the aerodynamic characteristics of train-induced aerodynamic pressure are rare. As the enclosed housing for sound emission alleviation is similar to a tunnel, the research achievements in the field of tunnel aerodynamics should be instructive for enclosed housing for sound emission alleviation. Many researchers have studied the train-induced aerodynamic pressure inside tunnels through field measurements, dynamic model experiments, and numerical simulations.

Kikuchi et al. [6], Fukuda et al. [7], Liu et al. [8-10], and Ko et al. [11] studied the aerodynamic pressure on a tunnel wall during the passage of trains using field measurements. Kikuchi et al. [6] investigated the wayside low-frequency noise on a tunnel portal created by passing the tunnel of a high-speed train. Their results indicated that the main components of low-frequency noise at the portal of the tunnel are pulsed micro pressure waves and continuous pressure waves. Fukuda et al. [7] investigated the distortion process of a pressure wave. They found that the compression wavefront becomes steep in the early stage and flattened in the later stage of propagation in the tunnel. Liu et al. [8] conducted a series of real vehicle tests on EMUs passing through the tunnel, analyzing pressure changes on the wall of the tunnel, the train wind in the tunnel, and the micro pressure waves at the tunnel entrance with different train speeds. They concluded that the three-dimensional effect of the tunnel entrance is obvious, and when the train is running at $200 \mathrm{~km} / \mathrm{h}$, the wind speed caused by the train exceeds the safe wind speed for the human body. Liu et al. [9] studied the influence law of train speed on pressure change, airflow velocity, and micro pressure waves. They found that the pressure change amplitude, airflow velocity, and micro pressure waves are proportional to the square of the train speed, the train speed and the cube of the train speed, respectively. Liu et al. [10] studied the 
interior pressure variations in high-speed trains passing through tunnels and found that the amplitude and duration of the initial compression effect on the train are independent of the tunnel length when a tunnel is longer than a certain length. Ko et al. [11] measured aerodynamic pressures in tunnels caused by passing high-speed trains and found that the pressure peaks were approximately proportional to the square of the train speed and decreased as the cross-sectional area of the tunnel increased. Field measurement is a direct and reliable method. Through field measurements, a researcher obtained the original data for the train-induced aerodynamic pressure inside tunnels.

Dynamic model experiments are also a reliable method used to investigate the aerodynamic pressure inside tunnels. Iida et al. [12] investigated the characteristics of the pressure wave and the generation process of micro pressure waves by model experiments. The relationship between the amplitude of a micro pressure wave and train speed was obtained. Bellenoue et al. [13] used a 1/77 scale test rig and simulated the first compression wave when a high-speed train enters a tunnel. The experimental results were verified through field observations carried out in the framework of the European Union research project TRANSAERO. Bellenoue and Kageyama [13] investigated the effects of the train/tunnel blockage ratio, the shape of the train nose and the geometry of the entrance hood on the pressure gradient of the compression wave generated by a high-speed train using moving model experiments. They reported that reducing the blocking rate can reduce the amplitude and pressure gradient of the compression wave and that increasing the nose length of the train can reduce the pressure gradient, but these actions have little effect on the amplitude of the pressure wave. Winslow et al. [14] carried out a 1/127 scale moving model experiment to investigate the effect of a scarfed portal on the compression wave generated by a train entering a tunnel. The results showed that optimizing the slope value at the oblique entrance of a tunnel can reduce the pressure gradient by up to $15 \%$. Their results revealed that with the distance from the tunnel entrance, the compression wave becomes a plane wave after it has propagated four times the tunnel diameter inside the tunnel. Iida et al. [15] analyzed the compression wave generated by a train entering a tunnel by performing a model experiment and found that an opening on the sidewall or roof of the tunnel entrance hood can reduce the pressure gradient of the compression wave generated by the entering train. A scaled moving model experiment was conducted to investigate the characteristics of pressure waves induced by entering a high-speed train tunnel [16]. The results revealed that pressure peaks were affected by the train speed and the nose shape; in addition, the initial pressure peak increased slightly with the length of the train. Doi et al. [17] developed a 1/30 scale moving model experimental facility to analyze pressure waves generated by high-speed trains passing through a tunnel. The experimental results agreed well with the field measurements. Heine et al. [18] investigated the effect of tunnel hoods on the pressure waves inside tunnels and concluded that tunnel hoods reduced the pressure gradient by approximately $44 \%$. Yang et al. [19] developed a large-scale ratio of a 1/8 moving model rig that can accelerate a training model to an actual Mach number to achieve an experimental simulation of a train passing through a tunnel or two trains intersecting in a tunnel. Zhang et al. [20] used a 1:20 scale moving model to study the pressures acting on train and tunnel surfaces as well as the effects of train speeds on these surfaces. They found that the pressure amplitude values on the surfaces of trains and tunnels and the micro pressure waves increased sharply with increasing train speed.

With the development of computer technology, numerical simulations have become increasingly popular and reliable. Ozawa et al. [21] simulated the transient flow field and compression wave induced by a high-speed train moving into a tunnel and found that the pressure gradient of the compression wave was related to the train position, the train shape and the tunnel cross-section. Kwon et al. [22] proposed a hybrid dimension method to investigate train-induced tunnel aerodynamics and greatly improved the calculation efficiency. Li et al. [23] obtained the magnitude of the pressure variation on both tunnels and trains when the train passed the tunnel through a numerical simulation. They concluded that the aerodynamic pressure on both the tunnel and train was approximately proportional 
to the square of the train speed. Uystepruyst et al. [24] investigated the effects of the shape, cross-section and length of the hood on the temporal gradient of the pressure wave generated by a high-speed train entering a tunnel. Chu et al. [25] simulated train-induced aerodynamic pressure in tunnels and found that the maximum and minimum pressures and force coefficients depended on the tunnel length, train length, train speed, and blockage ratio. Rabani et al. [26] concluded that the blockage ratio and train speed were the two main factors affecting the first pressure wave generated when a train enters a tunnel. Liu et al. [27] and Zhou et al. [28] numerically simulated the transient wind load generated by a train passing through a tunnel. Liu et al. [27] found that the pressure waves exhibit good one-dimensional characteristics during propagation in the tunnel. Zhou et al. [28] obtained the pressure change of the train and the tunnel and investigated the flow field around the train.

The above literature review shows that many previous studies have focused on the aerodynamic characteristics of train-induced aerodynamic pressure in tunnels. They help to better understand the aerodynamic characteristics of an enclosed housing for sound emission alleviation when a train passes through. However, because tunnels are rigid structures and are insensitive to dynamic loads, few previous studies have focused on the dynamic characteristics of wind loads. Enclosed housings for sound emission alleviation are always made of steel and are much more flexible and sensitive to dynamic loads. The dynamic characteristics of train-induced aerodynamic pressure on an enclosed housing for sound emission alleviation can act as control factors for the structural design. Consequently, in the present study, the unsteady aerodynamic pressure inside an enclosed housing for sound emission alleviation is numerically simulated when a CRH380 train passes through and exits at a speed of $350 \mathrm{~km} / \mathrm{h}$. The dynamic characteristics of the aerodynamic pressure are discussed in terms of wave propagation, impact effect, extreme pressure, duration of extreme pressure, dominant frequency and decay rate.

\section{Numerical Methodology}

\subsection{Geometry}

The present study numerically investigates the unsteady aerodynamic pressure of an enclosed housing for sound emission alleviation when a high-speed train passes through. CFD simulations are conducted using ANSYS Fluent software. A geometric model of a high-speed train is simplified as shown in Figure 1a. The details of the train, such as the pantograph, bogies, and wheels, are ignored. As the most common trains, the train model consists of eight coaches, including the head and tail coaches, and six intermediate coaches, with a total length $\left(L_{T}\right)$ of $203 \mathrm{~m}$ and a width $(W)$ and height $(H)$ of $3.38 \mathrm{~m}$ and $3.7 \mathrm{~m}$, respectively. Figure $1 \mathrm{~b}$ shows the geometry of the enclosed housing for sound emission alleviation. The model is the preliminary design of a project in a high-speed railway line. The length of the enclosed housing for sound emission alleviation is $840 \mathrm{~m}$, the radius of the cross-section is $6.913 \mathrm{~m}$, the height is $9.637 \mathrm{~m}$, the track spacing is $5.0 \mathrm{~m}$ and the cross-sectional area of the enclosed housing for sound emission alleviation is $110.5 \mathrm{~m}^{2}$. A universal beam $(\mathrm{H} 500 \times 300 \times 12 \times 25)$ is set up every two meters inside the housing for sound emission alleviation. 

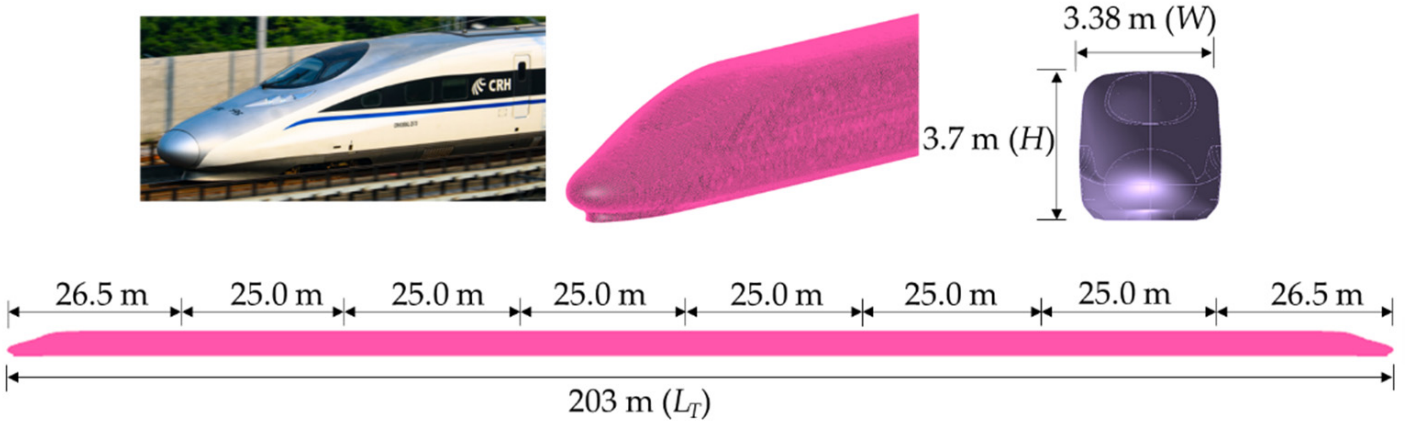

(a)
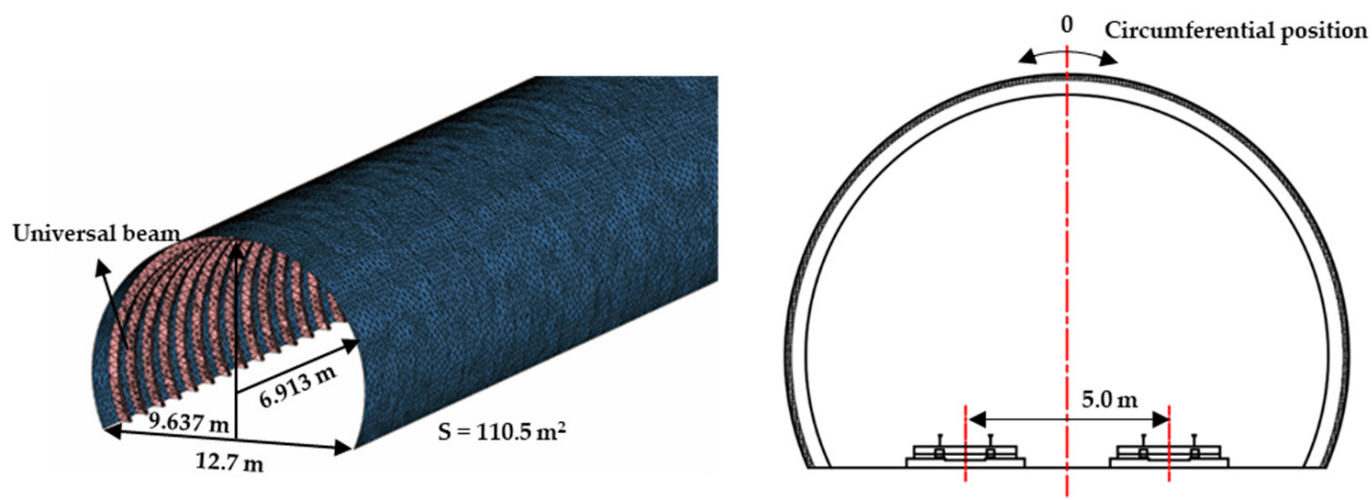

(b)

Figure 1. Computational models and surface meshes. (a) Train model. (b) Enclosed housing for sound emission alleviation.

\subsection{Computational Domain and Mesh}

Figure 2 shows the overview and cross-section of the computational domain. The computational domain is $(550 \mathrm{~m}+840 \mathrm{~m}+550 \mathrm{~m}) \times 50 \mathrm{~m} \times 50 \mathrm{~m}$ in volume and consists of three parts: the two acceleration domains at both ends with a length of $550 \mathrm{~m}(148.6 \mathrm{H})$ and the housing for sound emission alleviation domain at the center with a length $\left(L_{S}\right)$ of $840 \mathrm{~m}$. The boundary conditions of the computational domain are defined as shown in Figure $2 a$. The bottom surface is ground and set as a no-slip solid wall, while the other five surfaces are atmospheric condition and set as outlets with zero pressure [26,29]. The surfaces of the train body and the housing for sound emission alleviation are set as no-slip solid walls. The entire computational model uses a hybrid grid of tetrahedral unstructured grids and prismatic grids. In addition, the meshes on the train body and wall of the housing for sound emission alleviation are refined to improve the calculation accuracy.

To avoid the mesh size effect, a grid independence study was conducted before the formal simulations. Two different meshes with different numbers of cells were divided into two groups: coarse meshes ( 24 million) and fine meshes (32 million). Figure 3 shows the representative results obtained with the two meshes. When a train travels through the enclosed housing for sound emission alleviation at a speed of $350 \mathrm{~km} / \mathrm{h}$, the peak-to-peak aerodynamic pressure at the measuring point located at S2 is $1900.6 \mathrm{~Pa}$ and $1849.1 \mathrm{~Pa}$ for the two meshes, respectively, and the difference is $2.7 \%$; the mesh is independent of the simulation results. Therefore, the coarse mesh ( 24 million) is used as the calculation mesh in this paper.

The time step is set as $0.002 \mathrm{~s}$, which is smaller than the $0.0025 \mathrm{~s}$ used in Yang et al. [30], and the $0.005 \mathrm{~s}$ used in Li et al. [31]. The FVM was selected to discretize the computational domain. The second-order upwind scheme was chosen to discretize the convection and diffusion terms. The second-order implicit scheme was chosen to discretize the time derivative. SIMPLE was chosen as the pressure velocity coupling treatment, which was used by Ferziger and Peric [32], and the convection term applied the second-order upwind 
form. The $R e=4.4 \times 10^{7}$, the $\mathrm{y}+$ around the train surface is approximately 350 and the CFL number is 2 . The calculation of each case needs $168 \mathrm{~h}$ using $20 \times 24$ CPUs for parallel calculations.

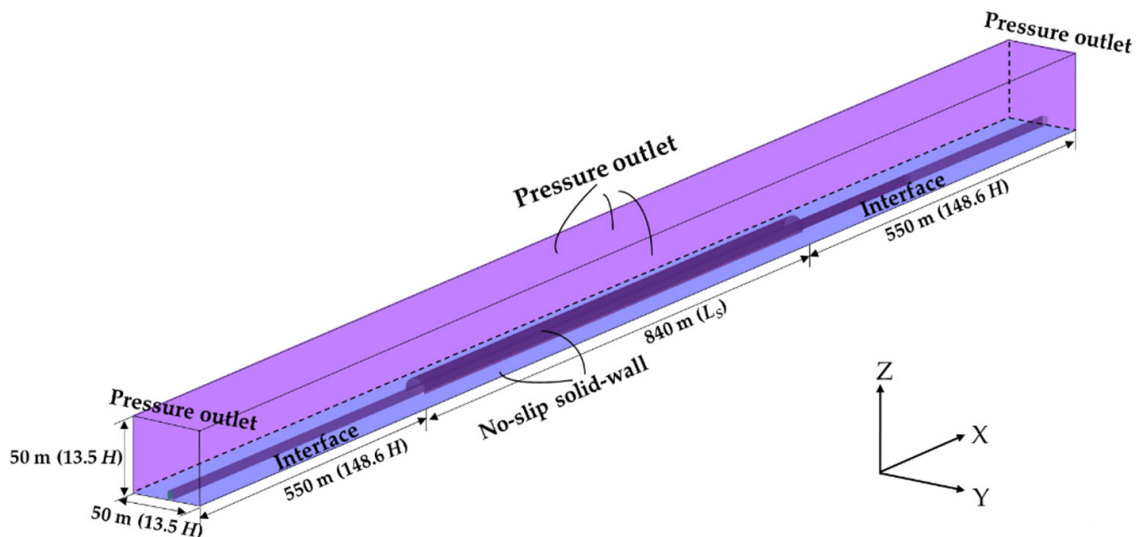

(a)

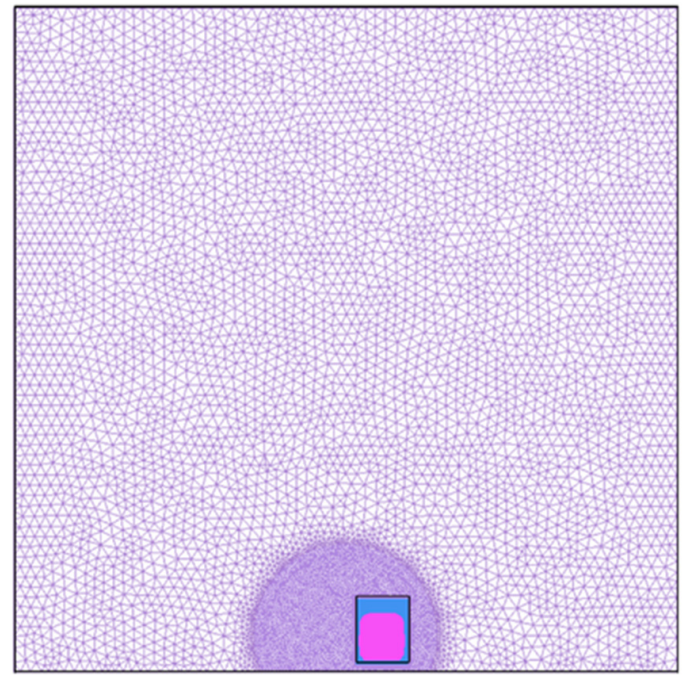

(b)

Figure 2. Overview and cross-section of the computational domain. (a) Overview of the computational domain. (b) Cross-section of the computational domain.

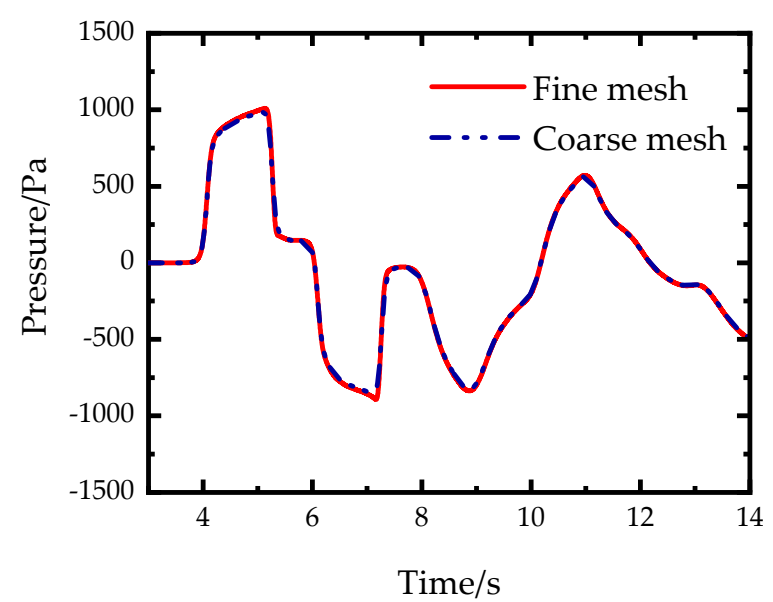

Figure 3. Pressure curves with different mesh resolutions. 
The dynamic mesh technique is utilized to simulate the movement of the train model [33-35]. There are three dynamic mesh update methods in FLUENT: smoothing, layering, and remeshing. In the present study, the layering method is adopted to implement the moving train relative to the housing for sound emission alleviation. The computational domain is divided into a stationary region and a moving region, as shown in Figure 4. The train and its surroundings are in the moving region, in which the mesh moves with the train. The movement of the train and its surrounding mesh is defined by a profile file. The outside is a stationary region containing the housing for sound emission alleviation. When the train moves forward, the dynamic layering method adds layers of cells in the field behind the moving region and deletes those in front of the moving region. The two regions exchange flow field information through the interface.

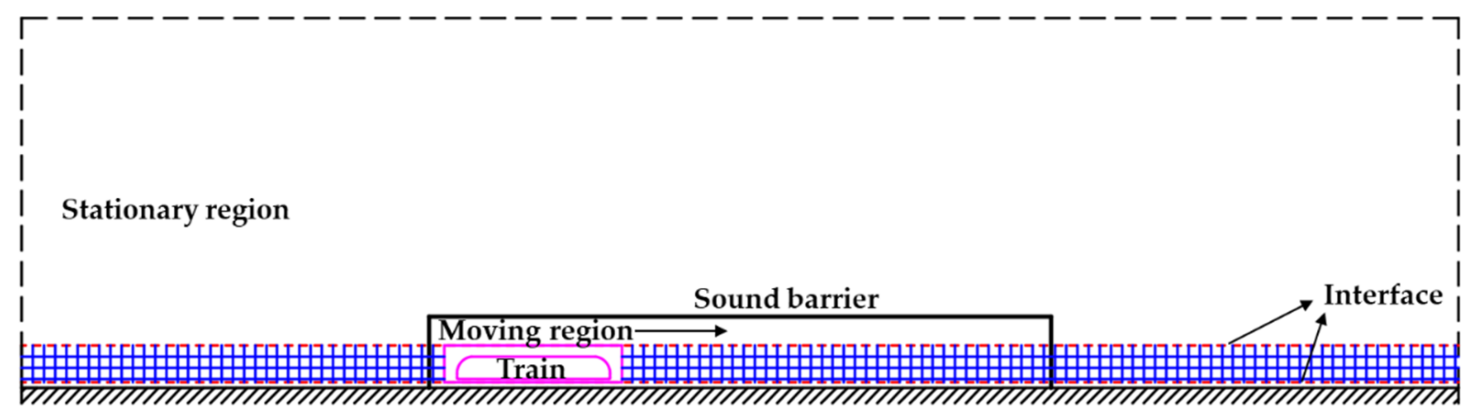

Figure 4. Schematic diagram of the dynamic layering method.

During the simulations, the train model starts to speed up with an acceleration of $48.61 \mathrm{~m} / \mathrm{s}^{2}$ at the location of $-250 \mathrm{~m}$ (the entrance of the housing for sound emission alleviation is at the location of $0 \mathrm{~m}$ ) and reaches the design speed at the location of $-152.78 \mathrm{~m},-152.78 \mathrm{~m}$ before the head coach enters the housing for sound emission alleviation, then passes through the housing for sound emission alleviation with a constant speed of $350 \mathrm{~km} / \mathrm{h}$, and finally exits the housing for sound emission alleviation. Figure 5 shows the speed strategy of the train model.

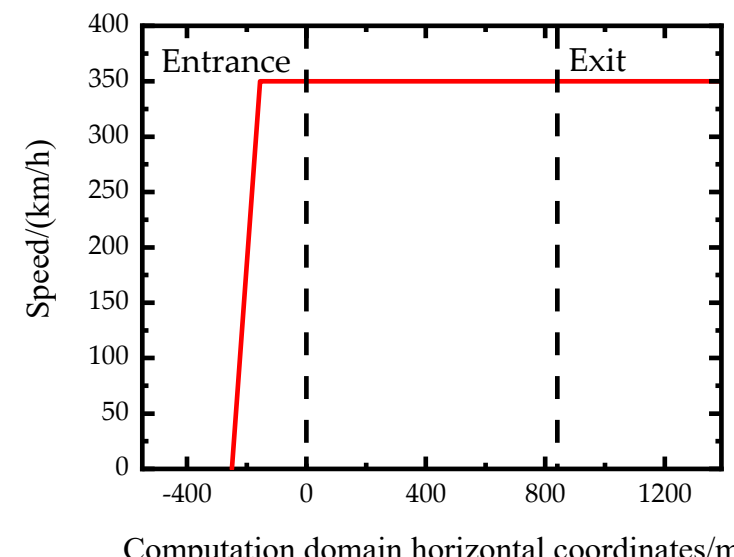

Figure 5. The speed strategy of the train model.

\subsection{Numerical Method}

When passing through the enclosed housing for sound emission alleviation, the train disturbs the surrounding air and generates strong wind. In the housing for sound emission alleviation, the air is strongly confined by the walls of the housing for sound emission alleviation and the train body; therefore, the flow field is three-dimensional, unsteady, viscous, compressible and turbulent. In the present study, the RANS method proved effective in simulating the flow field around a moving train [36-38], and the 
RNG k- $\varepsilon$ turbulent model was used to simulate the flow field, similar to Liu et al. [10], Yang et al. [30] and Huang et al. [39]. The number of iteration steps for each time step is preset to 50 steps $[29,40-42]$, and the residual is set to $10^{-6}$. This approach considers the influence of vortex factors and low Reynolds number effects in a turbulent flow and adds an extra term to the $\varepsilon$ equation of the standard $\mathrm{k}-\varepsilon$ model to effectively improve the accuracy. The governing equations are presented as below [25,43]:

Continuity Equation:

$$
\frac{\partial \rho}{\partial t}+\frac{\partial\left(\rho u_{i}\right)}{\partial x_{i}}=0
$$

Momentum Equation:

$$
\frac{\partial\left(\rho u_{i}\right)}{\partial t}+\frac{\partial}{\partial x_{j}}\left(\rho u_{i} u_{j}\right)=-\frac{\partial p}{\partial x_{i}}+\rho g \delta_{i 2}+\frac{\partial}{\partial x_{j}}\left[\mu\left(\frac{\partial u_{i}}{\partial x_{j}}+\frac{\partial u_{j}}{\partial x_{i}}-\frac{2}{3} \delta_{i j} \frac{\partial u_{l}}{\partial x_{l}}\right)\right]+\frac{\partial}{\partial x_{j}}\left(-\rho \overline{u_{i}^{\prime} u_{j}^{\prime}}\right)
$$

where $u$ and $u^{\prime}$ refer to the mean velocity and the pulsating velocity, respectively; $\rho$ represents the air density; $p$ is the static pressure; $-\rho \overline{u_{i}^{\prime} u_{j}^{\prime}}$ is the gradient of Reynolds stress, based on Boussinesq assumption:

$$
-\rho \overline{u_{i}^{\prime} u_{j}^{\prime}}=\mu_{t}\left(\frac{\partial u_{i}}{\partial x_{j}}+\frac{\partial u_{j}}{\partial x_{i}}\right)-\frac{2}{3}\left(\rho k+\mu_{t} \frac{\partial u_{k}}{\partial x_{k}}\right) \delta_{i j}
$$

where $\mu_{t}$ is the turbulent viscosity coefficient, as a function of turbulent kinetic energy $k$ and turbulent dissipation rate coefficient $\varepsilon$ :

$$
\mu_{t}=C_{\mu} \frac{k^{2}}{\varepsilon}
$$

The transport equation of the RNG $k-\varepsilon$ turbulence model is similar to the standard $k-\varepsilon$ model. Turbulent kinetic energy $(k)$ equation and dissipation rate $(\varepsilon)$ equation are:

$$
\begin{gathered}
\frac{\partial}{\partial t}(\rho k)+\frac{\partial}{\partial x_{i}}\left(\rho k u_{i}\right)=\frac{\partial}{\partial x_{j}}\left(\frac{\mu_{e f f}}{\alpha_{k}} \frac{\partial k}{\partial x_{j}}\right)+G_{k}-\rho \varepsilon-Y_{M} \\
\frac{\partial}{\partial t}(\rho \varepsilon)+\frac{\partial}{\partial x_{i}}\left(\rho \varepsilon u_{i}\right)=\frac{\partial}{\partial x_{j}}\left(\frac{\mu_{e f f}}{\alpha_{k}} \frac{\partial \varepsilon}{\partial x_{j}}\right)+C_{1 \varepsilon} \frac{\varepsilon}{k} G_{k}-C_{2 \varepsilon}^{*} \rho \frac{\varepsilon^{2}}{k}
\end{gathered}
$$

where $\mu_{e f f}$ is the effective dynamic viscosity equal to the sum of the molecular and turbulent viscosities, $G_{k}$ represents the turbulent energy generated by the laminar velocity gradient, the model parameters: $C_{1 \varepsilon}=1.42, C_{2 \varepsilon}^{*}$ is calculated as follows:

$$
C_{2 \varepsilon}^{*}=C_{2 \varepsilon}+\frac{C_{\mu} \eta^{3}\left(1-\eta / \eta_{0}\right)}{1+\beta \eta^{3}}
$$

where $C_{2 \varepsilon}=1.68, \eta_{0}=4.38, \beta=0.012, \eta=S k / \varepsilon, S$ is the skewness factor of turbulent velocity.

\subsection{Layout of Measurement Points}

The unsteady aerodynamic pressure generated by a high-speed train passing through and exiting the enclosed housing for sound emission alleviation was measured by setting pressure monitoring points on the wall of the housing for sound emission alleviation. Figure 6 shows the layout of the monitoring points. The monitoring points were symmetrically set at eleven cross-sections, referred to as $\mathrm{S} 1$ to S11, along the longitudinal direction, as shown in Figure 6a. Since the train model was assumed to move from the left side to the right side, section S1 is located at the entrance, and section S11 is located at the exit. The monitoring cross-section was refined at the middle of the housing for sound emission alleviation. There are five measuring points at each monitoring cross-section, as shown in Figure $6 b$. 


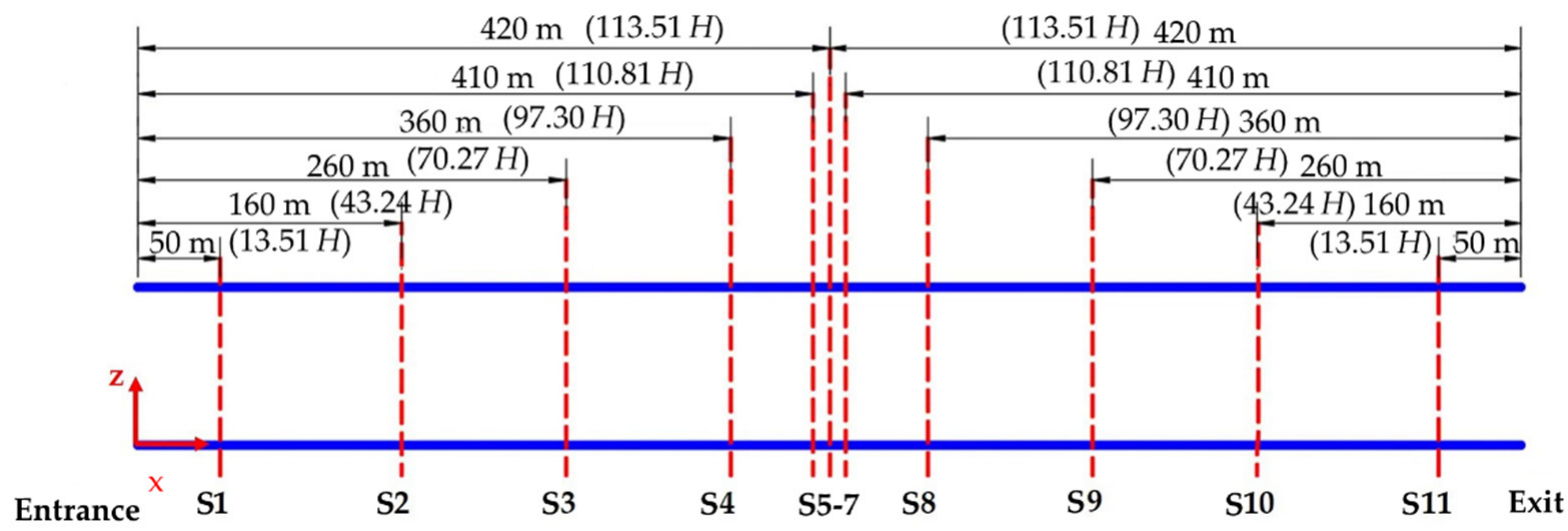

(a)

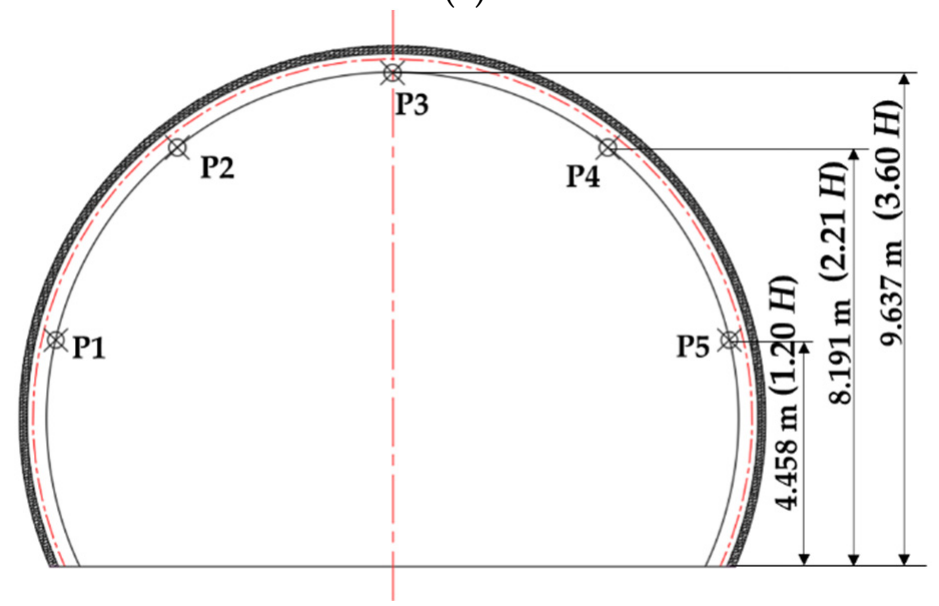

(b)

Figure 6. Measuring point distribution on the enclosed housing for sound emission alleviation. (a) Schematic diagram of the overall monitoring cross-sectional arrangement. (b) Layout of the measuring points on a monitoring cross-section.

\section{Validation}

To validate the effectiveness of the numerical simulation method, the motion model measurement conducted by Kim et al. [44] was calculated using the above numerical simulation method $[45,46]$, as shown in Figure 7 . For detailed information on the tests, please refer to the literature of Kim et al. [44]. Figure 8 compares the numerical and experimental pressure coefficients of PT1, PT2, PT3 and PT4, which are $8.5 \mathrm{~m}, 15.5 \mathrm{~m}$, $23.5 \mathrm{~m}$ and $30.5 \mathrm{~m}$ away from the tunnel inlet, respectively. The pressure coefficient is defined as:

$$
C p=\frac{P}{0.5 \rho v^{2}}
$$

where $P$ is the experimental or numerical aerodynamic pressure, $v$ is the train speed and $\rho$ is the air density. 


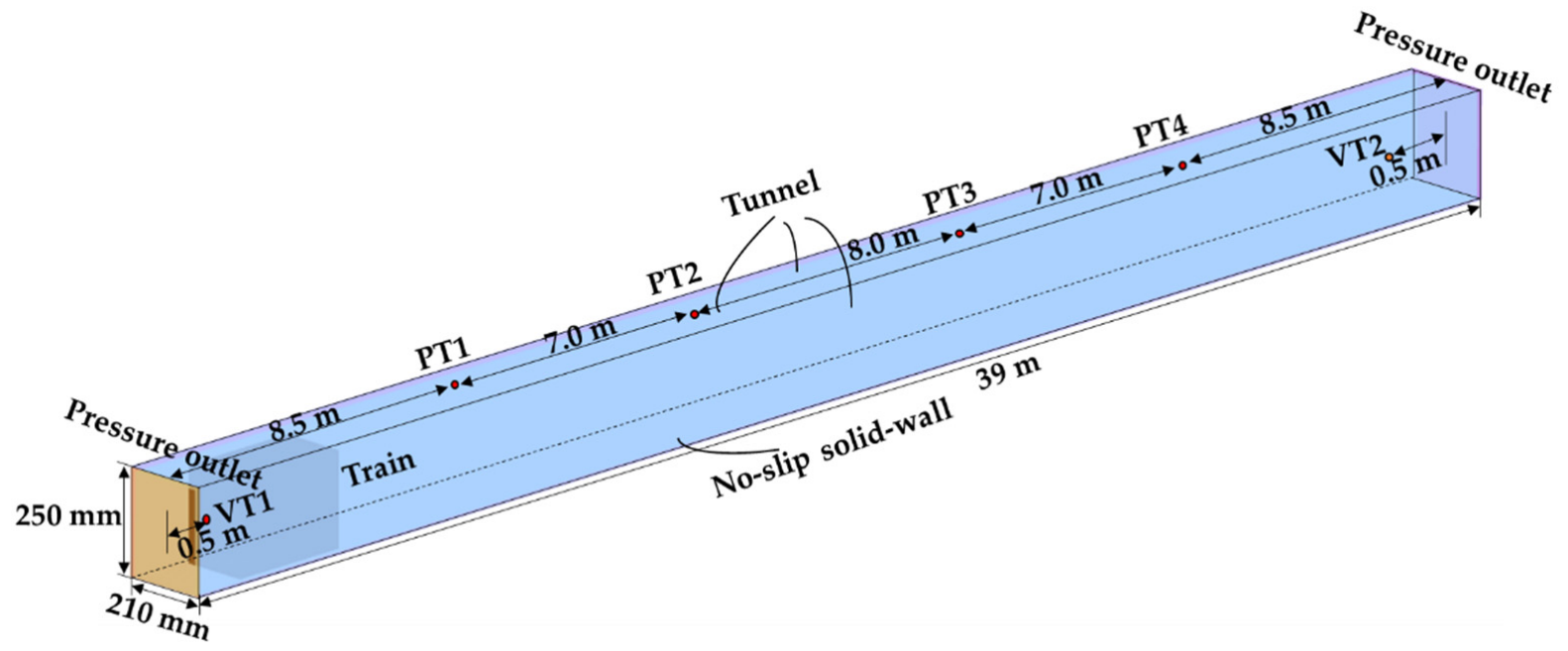

Figure 7. Schematic diagram of the numerical simulation calculation model.

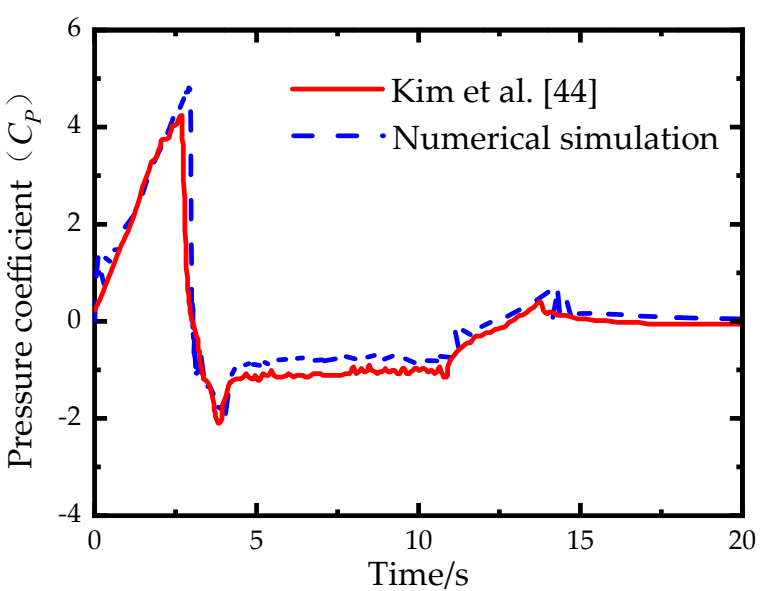

(a)

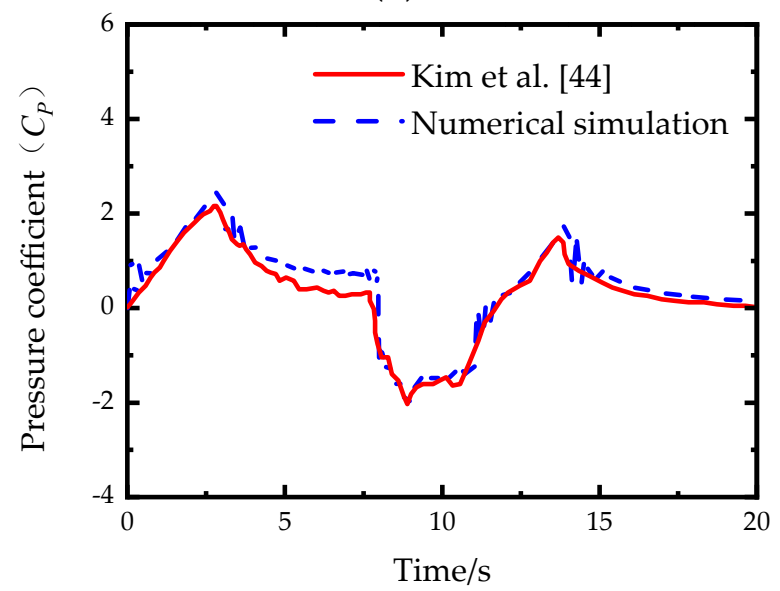

(c)

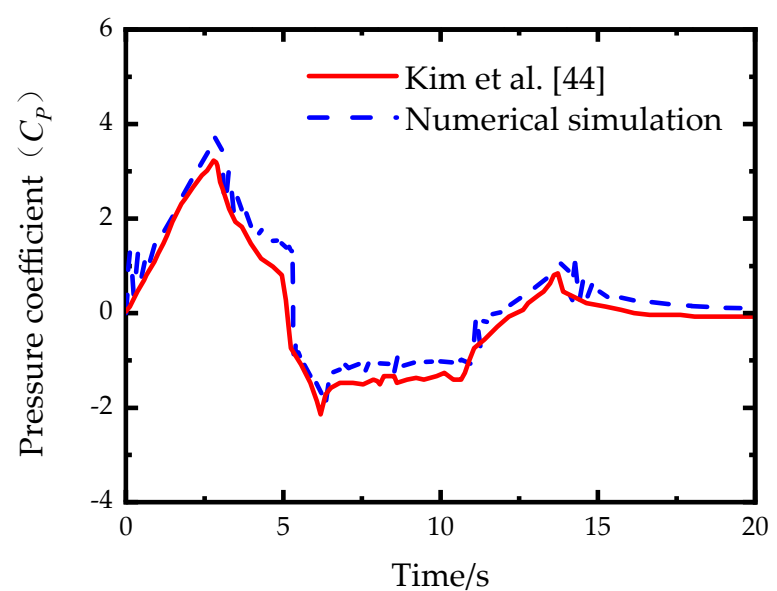

(b)

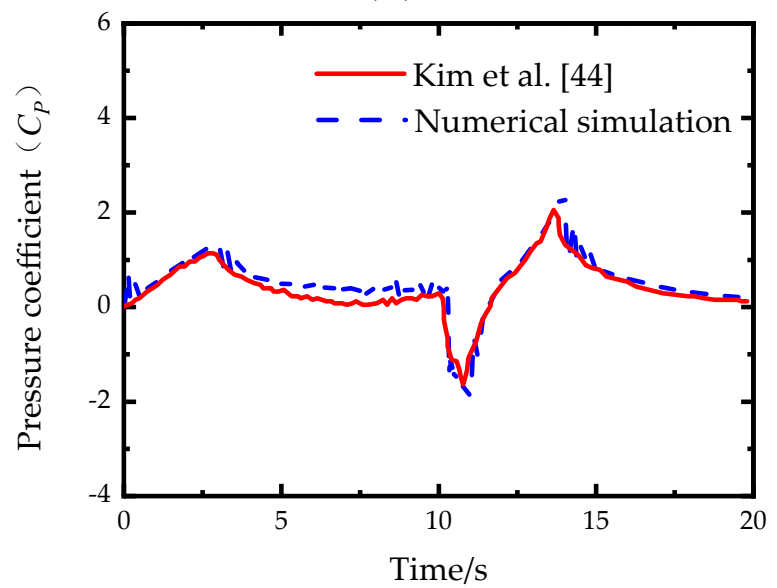

(d)

Figure 8. Comparison of $\mathrm{Cp}$ variations between the numerical simulation and the experimental results. (a) PT1. (b) PT2. (c) PT3. (d) PT4.

Figure 9 compares $\mathrm{u} / \mathrm{U}_{\mathrm{T} \_\mathrm{MAX}}$ variations between the numerical simulation and the experimental results of VT1 and VT2, which are $0.5 \mathrm{~m}$ and $38.5 \mathrm{~m}$ away from the tunnel inlet, respectively. $\mathrm{U}_{\mathrm{T} \_\mathrm{MAX}}$ is set to as $3.0 \mathrm{~m} / \mathrm{s}$. The comparison results show that the numerical 
calculation and the experimental results are in good agreement. Although the train speed of the validation case is much lower than that of the current work, the comparison results indicate that the numerical method adopted in this research is accurate to simulate the moving object-induced aerodynamic pressure and unsteady flow inside a tunnel structure. In addition, Liu et al. [45] and Izadi et al. [46] had used a similar method to simulate the aerodynamic pressure inside tunnels and obtained reasonable results. It indicates that the numerical method adopted in this research is accurate for obtaining the main characteristics of the flow field and aerodynamic pressure fluctuation when a high-speed train passes the housing for sound emission alleviation.

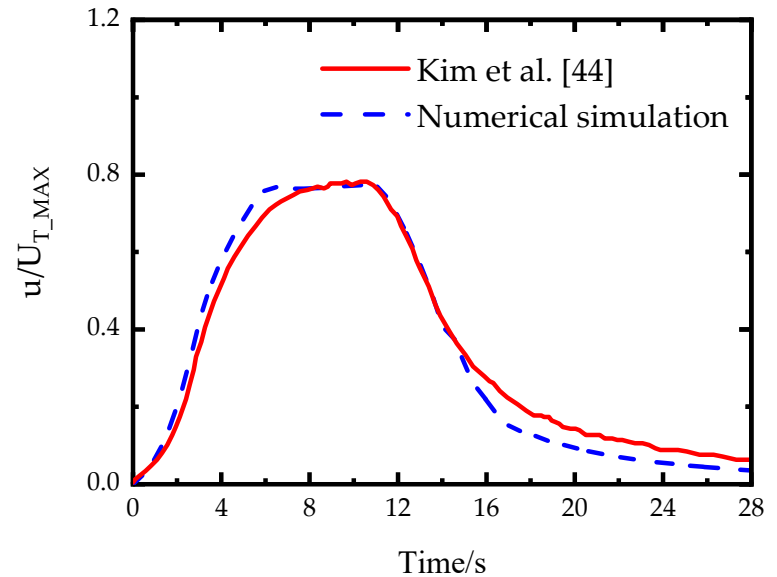

(a)

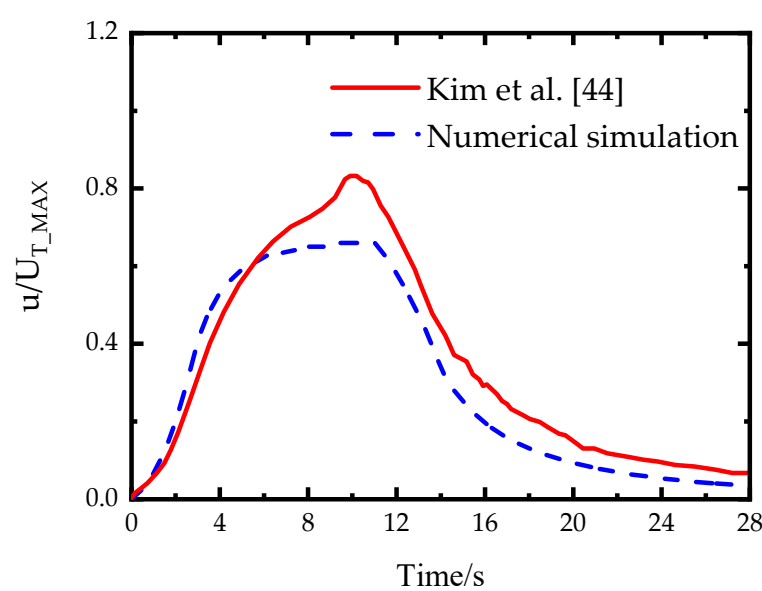

(b)

Figure 9. Comparison of $\mathrm{u} / \mathrm{U}_{\mathrm{T} \_\mathrm{MAX}}$ between the numerical and the experimental results. (a) VT1. (b) VT2.

\section{Results and Discussion}

The flow field is simulated using the given method when the train passes through the enclosed housing for sound emission alleviation at a speed of $350 \mathrm{~km} / \mathrm{h}$. The time history of the pressure on sections S1, S3, S6, S9 and S11 is monitored and shown in Figure 10. When the aerodynamic pressure is a pushing action, the aerodynamic pressure is defined as positive; conversely, when the aerodynamic pressure is a suction action, the pressure is defined as negative.

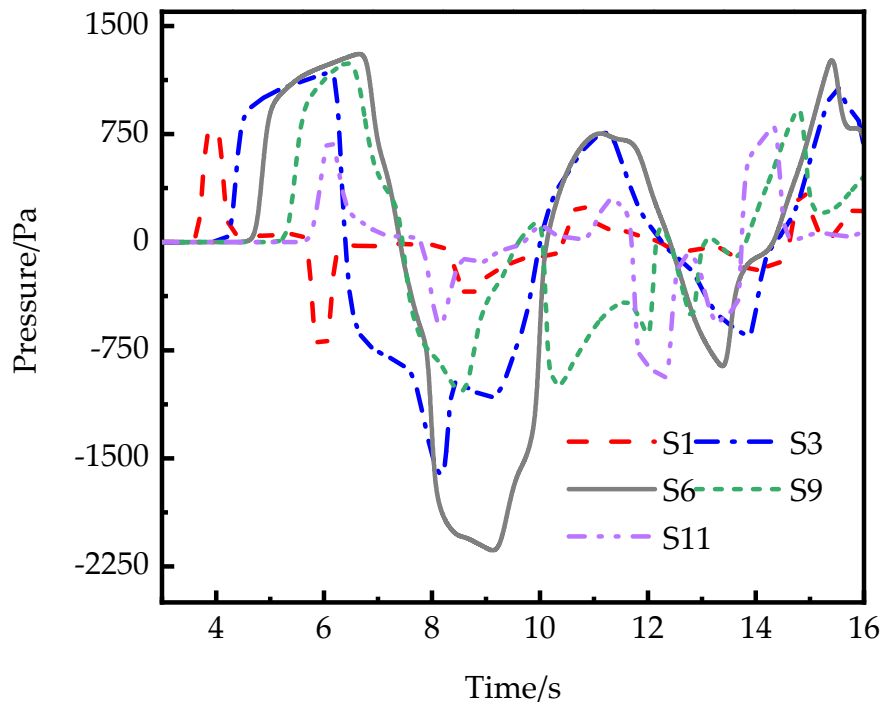

Figure 10. Time history of aerodynamic pressure on measuring points. 
The pressure curves show that all sections suffer both positive and negative aerodynamic pressures. The extreme pressures and variation tendencies are different in different sections depending on the distance away from the entrance. In the same section, the pressure curves share a similar tendency; in particular, the pressure curves are very close when the aerodynamic pressure is close to $0 \mathrm{~Pa}$. Meanwhile, the pressure amplitudes at the near-train side are always higher than those at the far-train side when extreme pressure appears. These results indicate that most of the time, the wind flow inside the housing for sound emission alleviation has one-dimensional characteristics; however, when extreme pressure appears, the wind flow should have a three-dimensional structure. These aerodynamic pressure characteristics on the enclosed housing for sound emission alleviation are similar to those for tunnels reported by Liu et al. [10]. However, as most enclosed housings for sound emission alleviation are made of steel structures and their stiffness is much lower than that of tunnels, they are more sensitive to train-induced wind loads, and consequently, the characteristics of the train-induced wind load are more important for the structural design of enclosed housing for sound emission alleviation.

Figure 10 shows that the aerodynamic pressure on the housing for sound emission alleviation is much more complicated than normal dynamic loads. The aerodynamic pressure is not a periodic wave and always rapidly increases or decreases. Therefore, the amplitude and frequency spectra are not enough to describe the dynamic characteristics of the aerodynamic pressure, and the impact effects should be considered. In the following sections, the dynamic characteristics of the aerodynamic pressure will be discussed in terms of wave propagation, impact effects, extreme pressure, duration of extreme pressure, dominant frequency and decay rate.

\subsection{Wave Propagation}

The aerodynamics inside the enclosed housing for sound emission alleviation are similar to those of tunnels $[47,48]$. When the train approaches the entrance of the enclosed housing for sound emission alleviation, the train head induces a compression wave, and the train rear motivates an expansion wave. Both compression and expansion waves propagate inside the housing for sound emission alleviation and reflect at both ends in sound velocity. The variation in aerodynamic pressure depends on the wave propagation. Figure 11 shows the details of the propagation of the aerodynamic pressure wave of P3 on section S9 when the train passes through. The black dotted line represents the position of the measuring point on the housing for sound emission alleviation wall, the red solid line (marked by $T_{N}$ ) is the running trajectory of the train head, the green dotted line (marked by $T_{R}$ ) is the running trajectory of the train rear, the blue solid lines (marked by $C_{W}$ ) present the propagation trajectory of the compression waves, and the blue dotted lines (marked by $E_{W}$ ) are the propagation trajectory of the expansion waves. The results show that a compression wave is generated at the instant the train head enters the housing for sound emission alleviation and then propagates inside the housing for sound emission alleviation at sound velocity. When the compression wave reaches section S9 at $t_{1}$, the monitored aerodynamic pressure first rapidly and then steadily increases. When the train tail enters the housing for sound emission alleviation, an expansion wave is generated and propagates inside the housing for sound emission alleviation at the sound velocity. When the expansion wave reaches S9 at $t_{2}$, the aerodynamic pressure begins to rapidly decrease. When the compression and expansion waves propagate to the exit of the housing for sound emission alleviation, they are reflected back as expansion and compression waves, respectively. At instant $t_{3}$, the reflected expansion wave reaches $S 9$, and the aerodynamic pressure continues to rapidly decrease. At instant $t_{4}$, the reflected compression wave reaches S9, the aerodynamic pressure increases. When the train head passes section S9 at $t_{5}$, the aerodynamic pressure decreases. After that, multiple compression and expansion waves are transmitted to section S6, and the pressure increases and decreases accordingly. The transmission of the aerodynamic pressure waves in the enclosed housing for sound emission alleviation is also consistent with those in tunnels, as reported by Liu et al. [47] 
and Ji et al. [48]. Figure 12 shows the pressure distribution on the wall of the housing for sound emission alleviation when $t=6 \mathrm{~s}$. The video of the train transition with pressure shown is given in the attachment.

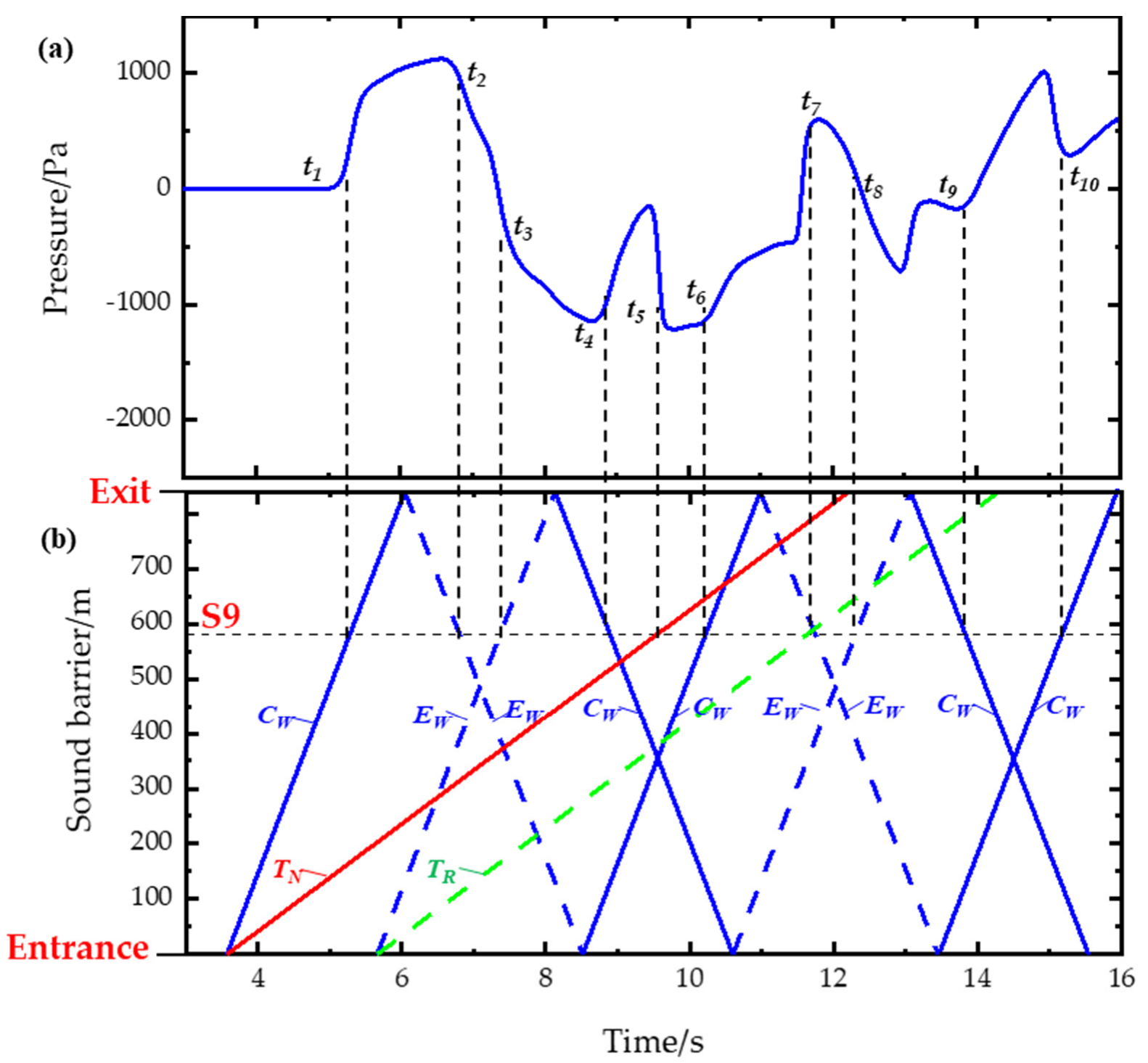

Figure 11. Pressure variations of $\mathrm{P} 3$ on the housing for sound emission alleviation section S9 and the propagation process of the pressure waves when the train passing through the housing for sound emission alleviation: (a) Time history of wind pressure of P3 at S9; (b) Propagation process of the pressure waves (The black dotted line in (b) represents the test section of (a), the red solid line is the running trajectory of the train head, marked by $T_{N}$; the green dotted line is the running trajectory of the train rear, marked by $T_{R}$; the blue solid lines present the propagation trajectory of the compression waves, marked by $C_{W}$; and the blue dotted lines are the propagation trajectory of the expansion waves, marked by $\left.E_{W}\right)$. 


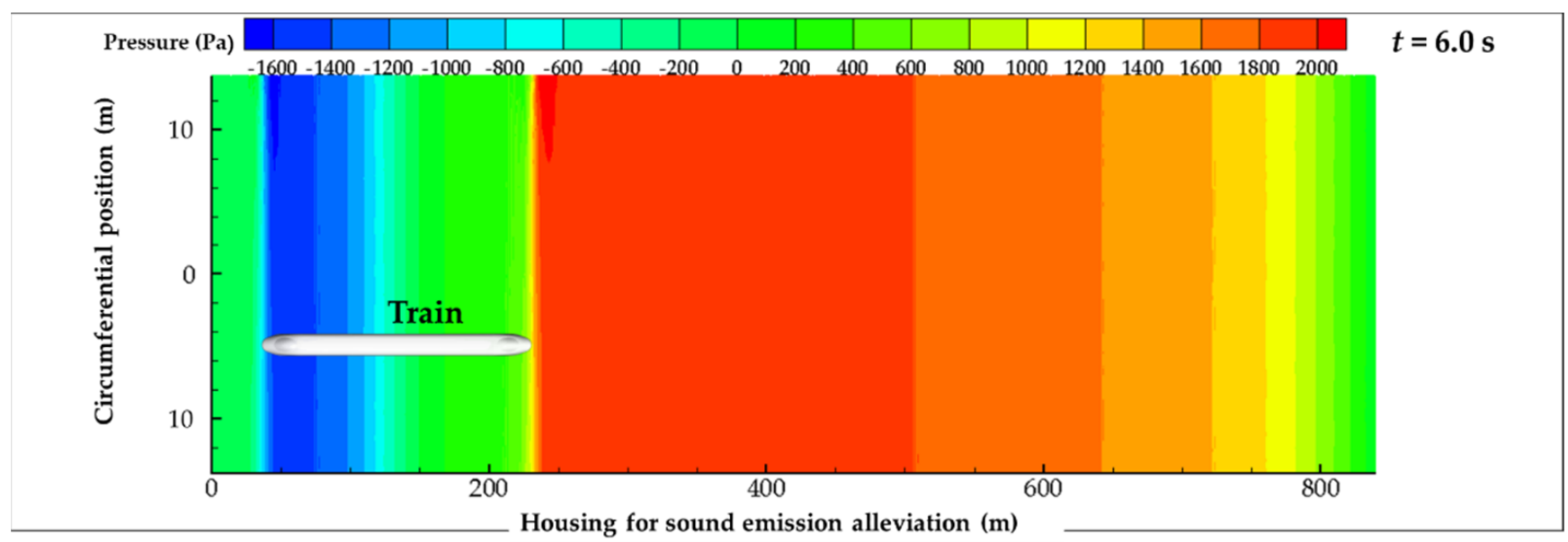

Figure 12. The pressure distribution on the wall of the housing for sound emission alleviation when $t=6 \mathrm{~s}$.

\subsection{Extreme Pressure, Duration of Extreme Pressure and Impact Effects}

As enclosed housings for sound emission alleviations are always made of steel structures, the extreme aerodynamic pressure, duration of the extreme pressure, and impact effects are key factors for the structural design. The extreme pressures are defined as the maximum positive or negative pressure acting on each section when the train passes through at a speed of $350 \mathrm{~km} / \mathrm{h}$. Table 1 shows the distributions of the positive extreme value, negative extreme value, and peak-to-peak aerodynamic pressure in the longitudinal direction. $P_{\text {pmax }}$ is the positive-extreme pressure, $P_{\text {nmax }}$ is the negative-extreme pressure, and the peak-to-peak pressure is the absolute difference of $P_{\text {pmax }}$ and $P_{n \max }\left(P_{\text {pmax }}-P_{n \max }\right)$. The results show that the extreme pressures are almost symmetrical against section $\mathrm{S} 6$, the middle section. The extreme aerodynamic pressure at the central region is always higher than those close to the entrance/exit. In particular, the negative extreme pressure drastically increases in the range of $150 \mathrm{~m}$ to $350 \mathrm{~m}$ from the entrance/exit and reaches $-2153 \mathrm{~Pa}$ at the middle section, more than two times higher than that at the entrance/exit sections. Different from the negative peak, the positive extreme pressure gradually increases from the entrance/exit to the middle section and reaches the maximum value of $1298 \mathrm{~Pa}$ at the middle section. The maximum peak-to-peak pressure is calculated as $3451 \mathrm{~Pa}$.

Table 1. Distribution of the extreme pressure in the longitudinal direction of the housing for sound emission alleviation.

\begin{tabular}{cccc}
\hline Sections & $\boldsymbol{P}_{\boldsymbol{p m a x}}(\mathbf{P a})$ & $\boldsymbol{P}_{\boldsymbol{n m a x}}(\mathbf{P a})$ & Peak-to-Peak (Pa) \\
\hline 1 & 1090 & -1020 & 2110 \\
2 & 1047 & -1088 & 2135 \\
3 & 1145 & -1607 & 2752 \\
4 & 1237 & -2076 & 3312 \\
5 & 1285 & -2111 & 3396 \\
6 & 1298 & -2153 & 3451 \\
7 & 1277 & -2023 & 3300 \\
8 & 1227 & -1963 & 3190 \\
9 & 1170 & -1212 & 2382 \\
10 & 944 & -909 & 1853 \\
11 & 799 & -936 & 17 \\
\hline
\end{tabular}

The time history of the train-induced aerodynamic pressure in Figure 10 shows the variation of the aerodynamic pressure is very complicated. It is hard to calculate the wind-induced response using this wind load. In the present study, an ideal model of the aerodynamic pressure is proposed using the duration, $T_{d}$, and the change rate of aerodynamic pressure, $\bar{P}$ and $P_{p \max }$ and $P_{n \max }$, as Figure 13 shows. 


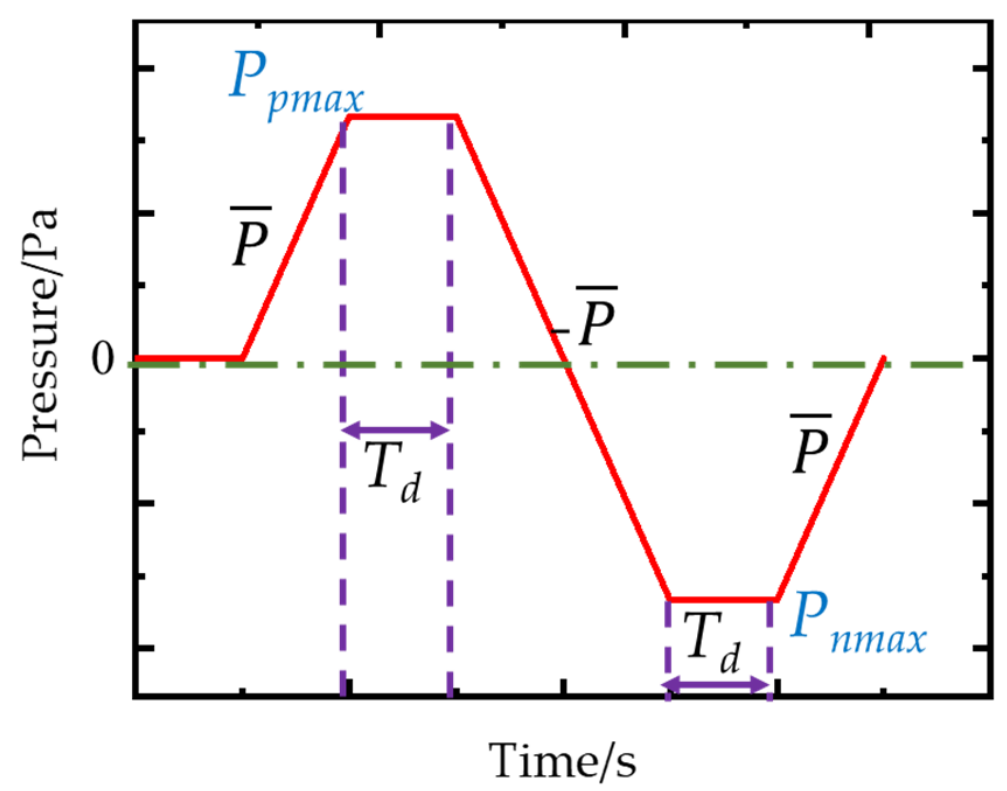

Figure 13. Ideal aerodynamic pressure model.

The duration $T_{d}$ is defined as the time when the aerodynamic pressure is higher than $85 \%$ of extreme pressure and the extreme pressure appears:

$$
T_{d}=\left.T 2\right|_{0.85 P_{\max }}-\left.T 1\right|_{0.85 P_{\max }}
$$

where $\left.T 1\right|_{0.85 P_{\max }}$ is the first instant when the pressure reaches $0.85 P_{\max }$ before the extreme pressure, $\left.T 2\right|_{0.85 P_{\max }}$ is the first instant when the pressure reaches $0.85 P_{\max }$ after the extreme pressure, and $P_{\max }$ represents both positive and negative extreme pressures.

The change rate of aerodynamic pressure $\bar{P}$ :

$$
\bar{P}=\frac{P_{i b}-P_{i h}}{t_{i b}-t_{i h}}
$$

where $P_{i h}$ and $P_{i b}$ are the aerodynamic pressures at two adjacent inflection points, $t_{i h}$ and $t_{i b}$ are the corresponding instants. In addition, the absolute difference, $\left|P_{i h}-P_{i b}\right|$, should be higher than $0.5 P_{\text {pmax }}$.

Table 2 summarizes the $T_{d}$ and maximum $\bar{P}$ of monitoring point $\mathrm{P} 3$ on sections $\mathrm{S} 1, \mathrm{~S} 3$, S6, S9, and S11. The sections close to both ends have shorter durations. The middle section $\mathrm{S} 6$ has the longest duration of the positive and negative extreme aerodynamic pressures. They are $1.41 \mathrm{~s}$ and $1.04 \mathrm{~s}$, respectively. Section S1, at the entrance of the enclosed housing for sound emission alleviation, has the highest positive and negative pressure change rate. They are $9.881 \mathrm{kPa} / \mathrm{s}$ and $-10.415 \mathrm{kPa} / \mathrm{s}$, respectively. In the other sections, the pressure change rate is relatively close, and the average values are calculated as $5.4 \mathrm{kPa} / \mathrm{s}$ and $-5.9 \mathrm{kPa} / \mathrm{s}$.

\begin{tabular}{|c|c|c|c|c|}
\hline \multirow{2}{*}{ Sections } & \multicolumn{2}{|c|}{$P_{\text {pmax }}$} & \multicolumn{2}{|c|}{$P_{n \text { max }}$} \\
\hline & $T_{d}(\mathrm{~s})$ & $\bar{P}(\mathrm{kPa} / \mathrm{s})$ & $T_{d}(\mathrm{~s})$ & $\bar{P}(\mathrm{kPa} / \mathrm{s})$ \\
\hline S1 & 0.222 & 9.881 & 0.154 & -10.415 \\
\hline S3 & 1.379 & 3.288 & 0.347 & -5.488 \\
\hline S6 & 1.410 & 5.780 & 1.041 & -6.569 \\
\hline S9 & 1.059 & 6.227 & 0.719 & -5.842 \\
\hline S11 & 0.356 & 6.366 & 0.526 & -5.609 \\
\hline
\end{tabular}

Table 2. The duration of the extreme pressure and the pressure change rate at different sections. 
Figure 14 compares the ideal aerodynamic pressure of the sections S1, S3, S6, S9 and S11. It shows that the ideal aerodynamic pressures under different sections are significantly different. They are much simpler than the original ones and can be adopted to simulate the structural responses of the housing for sound emission alleviation. However, whether the parameters in the ideal model are reasonable or not needs further study.

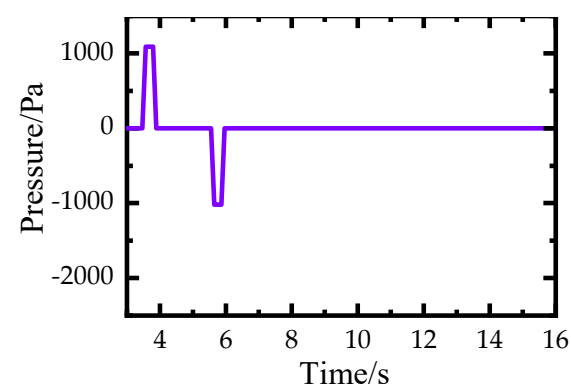

(a)

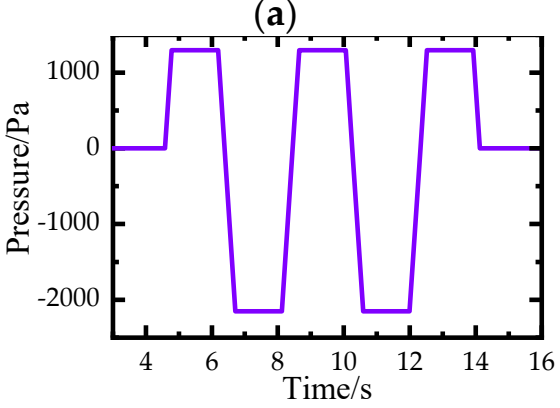

(c)

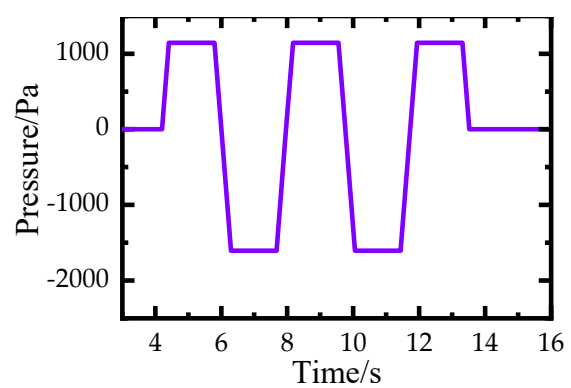

(b)

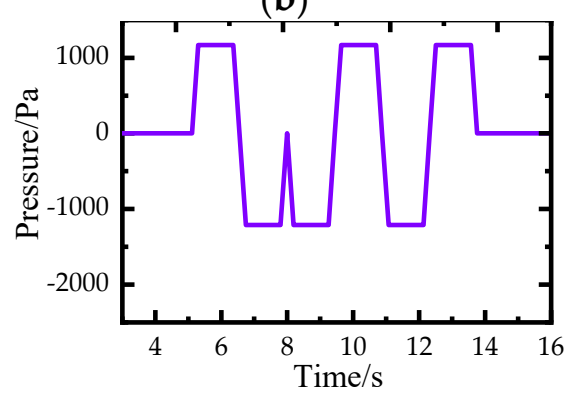

(d)

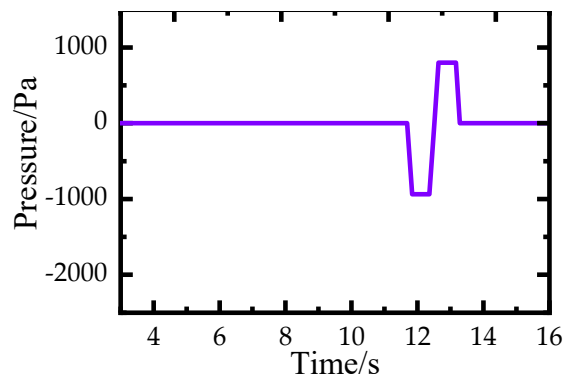

(e)

Figure 14. Ideal aerodynamic pressure at different sections. (a) S1. (b) S3. (c) S6. (d) S9. (e) S11.

As previously noted, when extreme pressures appear, the circumferential distribution of the aerodynamic pressure has obvious no uniformity characteristics. To reveal the circumferential distribution characteristics, the aerodynamic pressure on sections S1 and S6 at the instant when positive/negative extreme pressures appear is investigated and shown in Figures 15 and 16. The baseline values in Figure 15a,b are set as $700 \mathrm{~Pa}$ and $-600 \mathrm{~Pa}$, respectively. The values in Figure $16 \mathrm{a}, \mathrm{b}$ are set as $800 \mathrm{~Pa}$ and $-1300 \mathrm{~Pa}$, respectively. The results confirm that the pressure distribution at both sections S1 and S6 is asymmetrical in the circumferential direction. The pressure at the near side is always higher than that at the far side. However, the circumferential distribution of the aerodynamic pressure at both sections is different. 
(a)
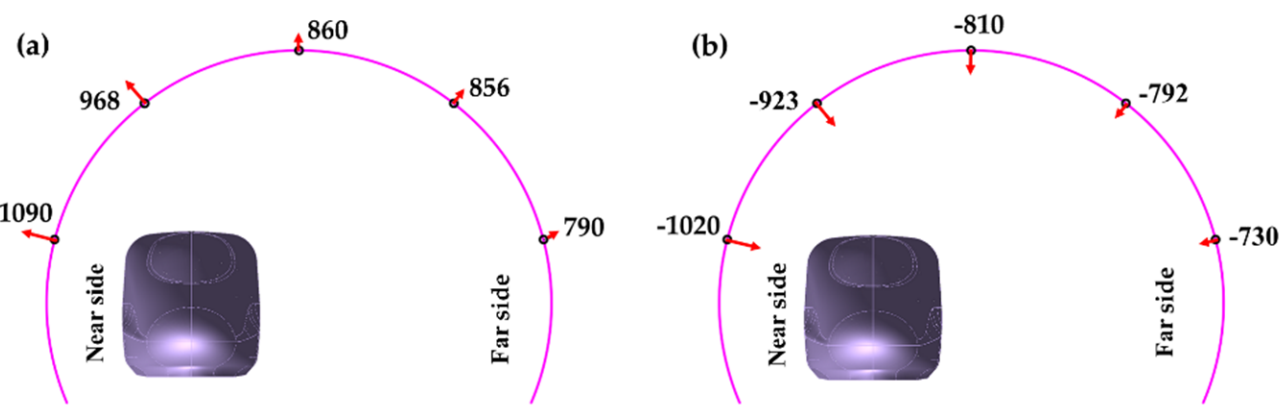

Figure 15. Pressure distribution on S1 when extreme pressure appears.
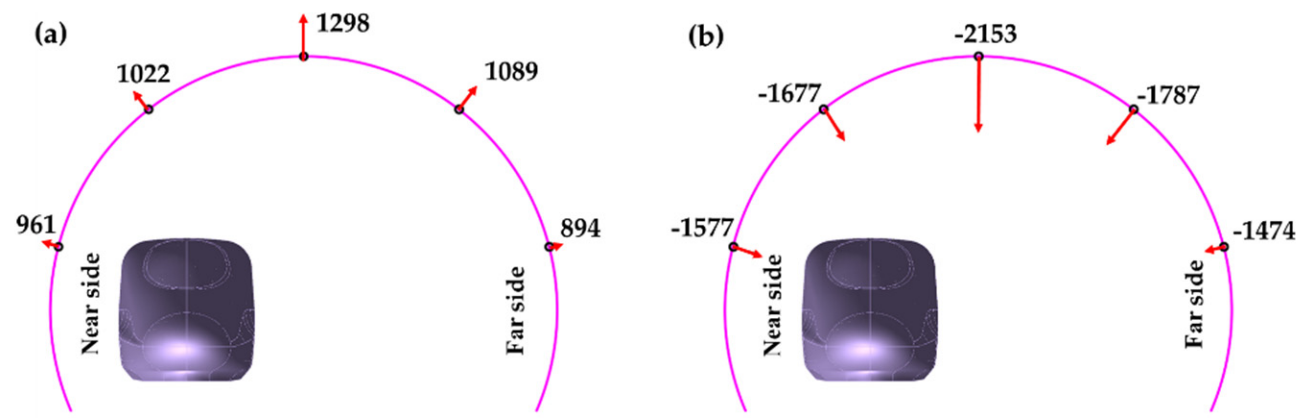

Figure 16. Pressure distribution on S6 when extreme pressure appears.

In section S1, aerodynamic pressure keeps decreasing from the near side to the far side. In particular, the positive and negative pressures on the near side are $37.97 \%$ and $39.73 \%$ higher than those on the far side, respectively. However, in section S6, the highest aerodynamic pressure appears at the top point P3. The positive and negative extreme pressures at $\mathrm{P} 3$ are $45.2 \%$ and $46.1 \%$ higher than those on the far side, respectively. This obvious no uniformity of the aerodynamic pressure should be carefully considered during the structural design of an enclosed housing for sound emission alleviation.

\subsection{Dominant Frequency and Decay Rate of the Aerodynamic Pressure after the Train Exits}

After the train exits the enclosed housing for sound emission alleviation, as the pressure wave continues to propagate inside the housing for sound emission alleviation, the aerodynamic pressure does not immediately revert to zero but remains varying. Figure 17 shows the pressure curves of $\mathrm{P} 3$ on sections after the train traverses the exit of the housing for sound emission alleviation. The results show that the pressure curves, in particular at the central sections, become periodic waves, and the amplitude gradually decreases, similar to the free vibration decay curves. In addition, the pressure wave is much more periodic, and its amplitude is much higher in the central region than that close to both ends. These characteristics are different from those when the train is passing inside the housing for sound emission alleviation. Consequently, the dominant frequency and decay rate of the pressure curves are analyzed as follows.

The dominant frequency of the aerodynamic pressure at the monitoring points in each section is obtained through spectral analyses. Figure 18 shows the calculated power spectrum density curves of the pressure of $\mathrm{P} 3$ on sections after the train traverses the exit of the housing for sound emission alleviation from 14.3-45 s and the sampling frequency is $500 \mathrm{~Hz}$. In all sections, the dominant frequency is equal to $0.2 \mathrm{~Hz}$. In fact, the dominant frequency can be theoretically derived using the propagation law of the pressure wave. When a compression wave reaches the monitoring point, the pressure reaches a positive extreme value; then, the expansion wave is reflected to be an expansion wave at one end of the housing for sound emission alleviation. When the expansion wave reaches the monitoring point, the extreme pressure is negative. After that, the expansion wave is reflected to be a compression wave again at another end of the housing for sound emission 
alleviation. When the new compression wave reaches the monitoring point, the pressure reaches the next positive extreme value. During this cycle, both compression and expansion waves travel the entire housing for sound emission alleviation once under the sound velocity. Consequently, the dominant frequency can be expressed as:

$$
f=\frac{v}{2 l}=0.2 \mathrm{~Hz}
$$

where $l$ is the length of the housing for sound emission alleviation and $v$ is the sound velocity. This formula is the same as that proposed by Liu et al. [47] in tunnel aerodynamics.

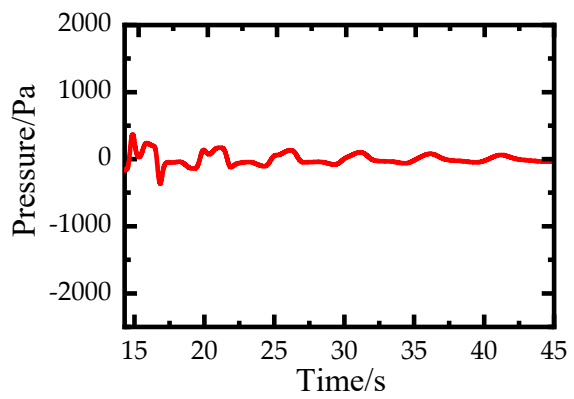

(a)

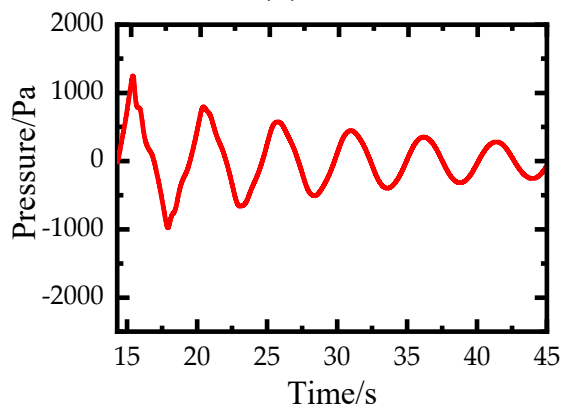

(c)

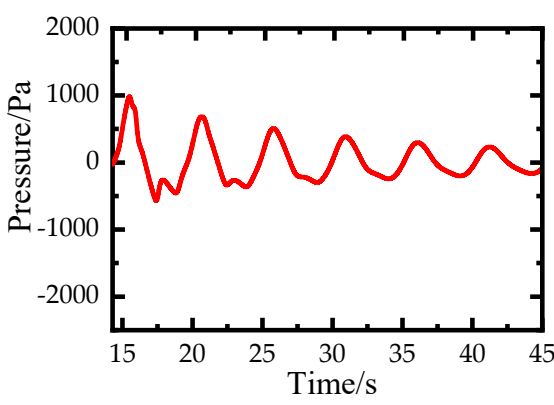

(b)

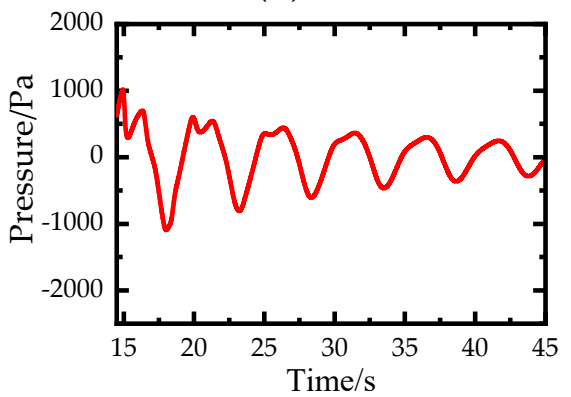

(d)

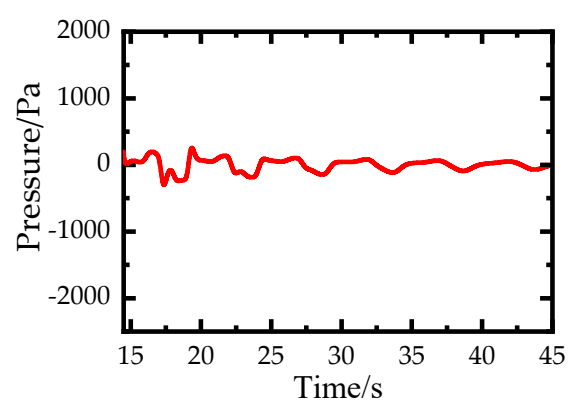

(e)

Figure 17. Pressure curves of different measuring points for the train passing through the housing for sound emission alleviation. (a) S1. (b) S3. (c) S6. (d) S9. (e) S11. 


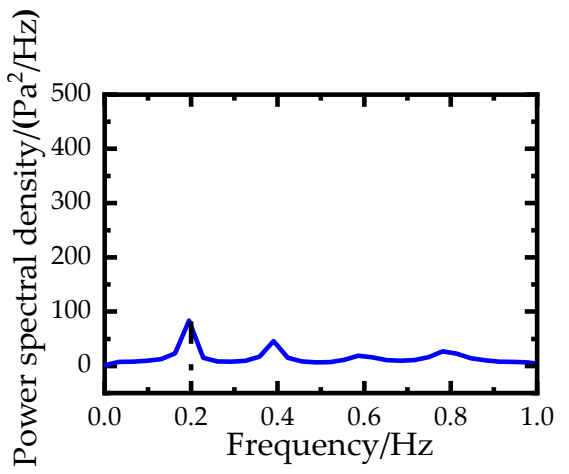

(a)

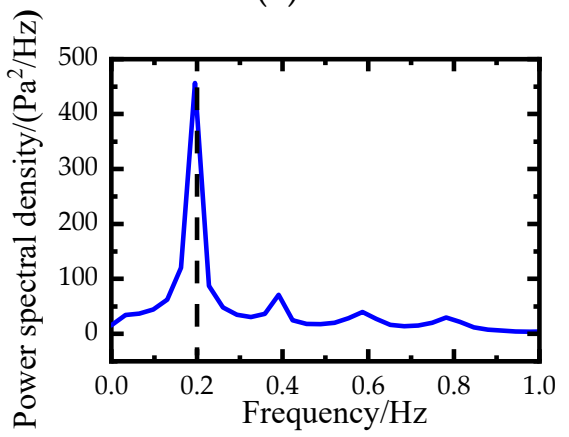

(c)

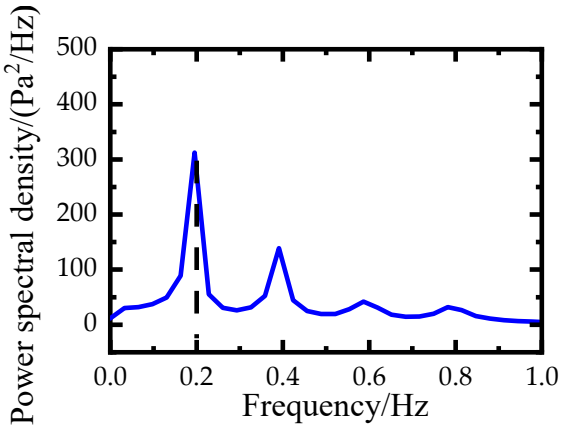

(b)

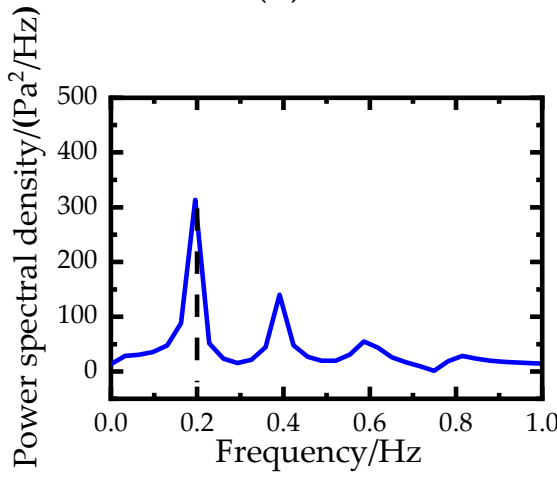

(d)

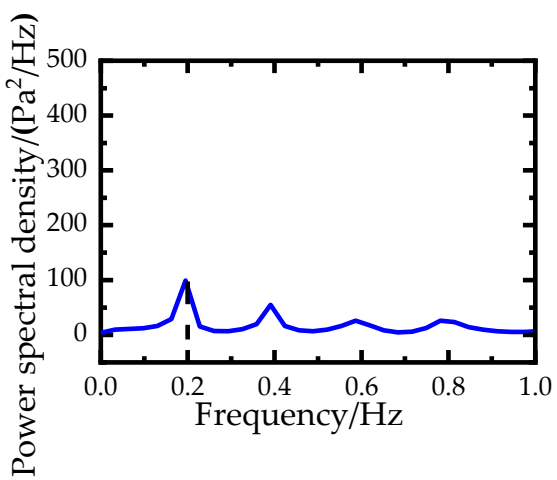

(e)

Figure 18. Pressure curves of different measuring points for the train passing through the housing for sound emission alleviation. (a) S1. (b) S3. (c) S6. (d) S9. (e) S11.

During the propagation, the strength of the aerodynamic pressure decreases due to the friction and refection effects. This dynamic process is important for the structure design. In order to evaluate the attenuation characteristic, the decay rate $\delta$ of the aerodynamic pressure is defined as [49]:

$$
\delta=\ln \left(\frac{A_{K}}{A_{K+1}}\right)
$$

where $A_{K}$ is a pressure extreme in the process of pressure decay, $A_{K+1}$ is the next pressure extreme after a cycle. The definition of the decay rate of the aerodynamic pressure is similar to that of a damped free vibration.

Figure 19 shows the pressure extremes envelope and the decay rate of the aerodynamic pressure fitted using Equation (11). The decay rate of the aerodynamic pressure on all sections is close, and the average decay rate is calculated as 0.262 . The highest decay rate is 0.277 in the middle section. Both decay rate and the dominant frequency are key parameters for the structural design of the enclosed housing for sound emission alleviation because they are necessary when the engineer evaluates the fatigue life. 


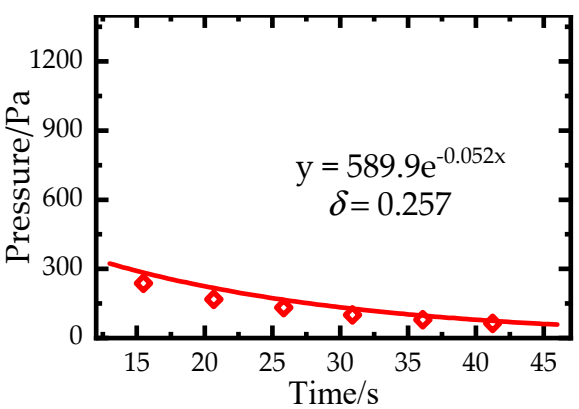

(a)

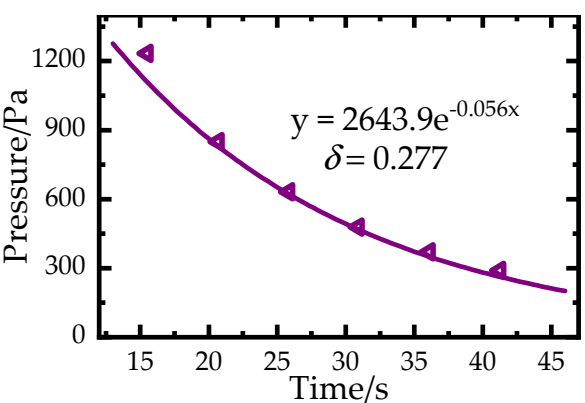

(c)

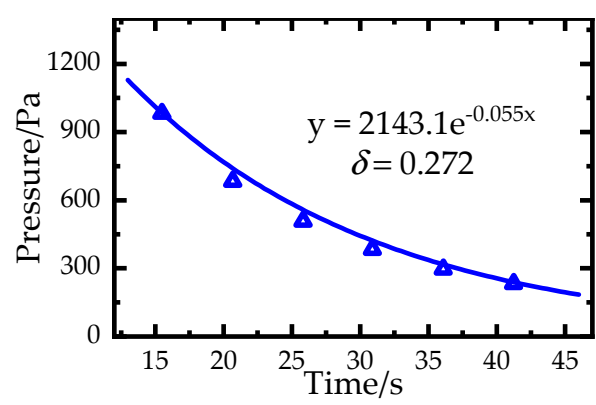

(b)

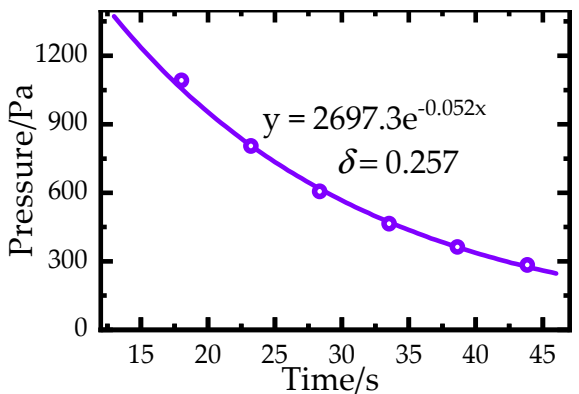

(d)

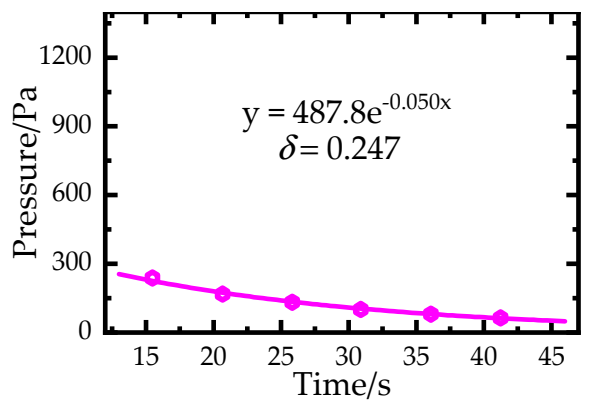

(e)

Figure 19. Pressure wave attenuations of different sections. (a) S1. (b) S3. (c) S6. (d) S9. (e) S11.

\section{Conclusions}

Consequently, in the present study, the unsteady aerodynamic pressure inside an enclosed noise barrier is numerically simulated when a CRH380 train [29] passes through and exits at a speed of $350 \mathrm{~km} / \mathrm{h}$ by using the dynamic mesh method. The numerical method is firstly validated by comparing the numerical results with experimental results using a benchmark case. Then, the dynamic characteristics of the aerodynamic pressure are discussed in terms of wave propagation, impact effect, extreme pressure, duration of extreme pressure, dominant frequency and decay rate. The results show that the original reason for the variation of the aerodynamic pressure is the wave propagation process inside the noise barrier, similar to those inside of a tunnel. The extreme aerodynamic pressure at the central region is always higher, and the maximum peak-to-peak pressure reaches $3451 \mathrm{~Pa}$. An ideal model of aerodynamic pressure of enclosed noise barriers is proposed using the duration of the extreme aerodynamic pressure and the pressure change rate, which is a cost-effective model for structure design. After the train exits the housing for sound emission alleviation, the aerodynamic pressure reverts to periodic decay curves. The dominant frequency and decay rate are proposed to express the dynamic characteristics. The main conclusions are summarized as follows: 
(1) The unsteady aerodynamic pressure is complicated and aperiodic when the train is running in the enclosed housing for sound emission alleviation. The reasons for the variation in the aerodynamic pressure are clearly caused by the propagation of the aerodynamic pressure wave, similar to that in a tunnel.

(2) The extreme aerodynamic pressure at the central region is always higher than those close to the entrance and exit. In particular, negative and positive extreme pressures appearing in the middle section are $-2153 \mathrm{~Pa}$ and $1298 \mathrm{~Pa}$, respectively. The maximum peak-to-peak pressure is $3451 \mathrm{~Pa}$.

(3) To further quantify the dynamic characteristics of the train-induced aerodynamic pressure on the housing for sound emission alleviation, an ideal model of aerodynamic pressure is proposed using the duration of the extreme aerodynamic pressure and the pressure change rate. The longest duration of the extreme aerodynamic pressure appears in the middle section, and the highest pressure change rate occurs at the entrance section. In other sections, the pressure change rate is relatively close. The ideal model is much simpler than the original aerodynamic pressure and can be adopted to calculate the structural responses of the housing for sound emission alleviation. The rationality of the parameters in the ideal model needs further studies.

(4) For the special enclosed housing for sound emission alleviation, the longest durations of the positive and negative extreme aerodynamic pressures are calculated as $1.41 \mathrm{~s}$ and $1.04 \mathrm{~s}$, respectively. The highest positive and negative pressure change rates are calculated as $9.881 \mathrm{kPa} / \mathrm{s}$ and $-10.415 \mathrm{kPa} / \mathrm{s}$, respectively. In other sections, the average pressure change rate is calculated as $5.4 \mathrm{kPa} / \mathrm{s}$ and $-5.9 \mathrm{kPa} / \mathrm{s}$.

(5) After the train exits the housing for sound emission alleviation, the aerodynamic pressure reverts to periodic decay curves. The pressure amplitude at the central region is always higher than those close to the entrance/exit. To better understand the aerodynamic pressure in this process, the dominant frequency and decay rate are proposed to express the dynamic characteristics. For the special enclosed housing for sound emission alleviation, the dominant frequency is identified as $0.2 \mathrm{~Hz}$, and the decay rate is calculated as 0.262 .

Author Contributions: All the authors made significant contributions to the work. H.J., X.J. and X.H. conceived this study; H.J., X.J. and X.H. completed the numerical calculations and analyzed the data; X.H. provided advice for the preparation and revision of the paper; H.J., X.J. and X.H. wrote the paper; S.Z., J.Z. and H.Z. reviewed the manuscript for scientific contents. All authors have read and agreed to the published version of the manuscript.

Funding: The numerical calculations in this paper have been done on the supercomputing system of the National Supercomputing Center in Changsha. This research was financially supported by the National Natural Science Foundations of China (No. 52078502, 51925808, U1934209) and the Nat-ural Science Foundations of Hunan Province, China (No. 2019JJ50819).

Institutional Review Board Statement: Not applicable.

Informed Consent Statement: Not applicable.

Data Availability Statement: Data are contained within this article.

Conflicts of Interest: The authors declare no conflict of interest.

\section{References}

1. Planning Engineering Consulting + Services China Ltd. Consultation Report of the Noise Barriers in Chinese Railway Passenger Dedicated Line. 2007.

2. Baker, C.; Jordan, S.; Gilbert, T.; Quinn, A.; Sterling, M.; Johnson, T.; Lane, J. Transient aerodynamic pressures and forces on trackside and overhead structures due to passing trains. Part 1: Model scale experiments; Part 2: Standards applications. Proc. Inst. Mech. Eng. Part F J. Rail Rapid Transit 2014, 228, 37-70. [CrossRef]

3. Lü, M.; Li, Q.; Ning, Z.; Ji, Z. Study on the aerodynamic load characteristic of noise reduction barrier on high-speed railway. J. Wind. Eng. Ind. Aerodyn. 2018, 176, 254-262. [CrossRef] 
4. Xiong, X.H.; Li, A.H.; Liang, X.F.; Zhang, J. Field study on high-speed train induced fluctuating pressure on a bridge noise barrier. J. Wind. Eng. Ind. Aerodyn. 2018, 177, 157-166. [CrossRef]

5. Soper, D.; Gillmeier, S.; Baker, C.; Morgan, T.; Vojnovic, L. Aerodynamic forces on railway acoustic barriers. J. Wind. Eng. Ind. Aerodyn. 2019, 191, 266-278. [CrossRef]

6. Kikuchi, K.; Iida, M.; Takasaki, T.; Takami, H. Field Measurement of Wayside Low-Frequency Noise Emitted from Tunnel Portals and Trains of High-Speed Railway. J. Low Freq. Noise Vib. Act. Control 2005, 24, 219-231. [CrossRef]

7. Fukuda, T.; Ozawa, S.; Iida, M.; Takaski, T.; Wakabayashi, Y. Distortion of compression wave propagating through very long tunnel with slab tracks. JSME Int. J. Ser. B 2006, 49, 1156-1164. [CrossRef]

8. Liu, T.H.; Tian, H.Q.; Jin, X.S. Experimental study of full-scale train on aerodynamics in tunnel. Acat. Aerodyn. Sin. 2008, 26, 42-46. (In Chinese)

9. Liu, T.H.; Tian, H.Q.; Liang, X.F. Aerodynamic Effects Caused by Trains Entering Tunnels. J. Transp. Eng. 2010, 136, 846-853. [CrossRef]

10. Liu, T.H.; Chen, X.D.; Li, W.H.; Xie, T.Z.; Chen, Z.W. Field study on the interior pressure variations in high-speed trains passing through tunnels of different lengths. J. Wind. Eng. Ind. Aerodyn. 2017, 169, 54-66. [CrossRef]

11. Ko, Y.Y.; Chen, C.H.; Hoe, I.T.; Wang, S.T. Field measurements of aerodynamic pressures in tunnels induced by high speed trains. J. Wind. Eng. Ind. Aerodyn. 2012, 100, 19-29. [CrossRef]

12. Iida, M.; Tanaka, Y.; Kikuchi, K.; Fukuda, T. Pressure waves radiated directly from tunnel portals at train entry or exit. Q. Rep. RTRI 2001, 42, 83-88. (In Japanese) [CrossRef]

13. Bellenoue, M.; Moriniere, V.; Kageyama, T. Experimental 3-D Simulation of the Compression Wave, due to Train-Tunnel Entry. J. Fluid Struct. 2002, 16, 581-595. [CrossRef]

14. Winslow, A.; Howe, M.S.; Iida, M. Influence of a Scarfed Portal on the Compression Wave Generated by a High-Speed Train Entering a Tunnel. J. Low Freq. Nois. 2009, 24, 203-217. [CrossRef]

15. Iida, M.; Kikuchi, K.; Fukuda, T. Analysis and Experiment of Compression Wave Generated by Train Entering Tunnel Entrance Hood. JSME Int. J. Ser. B 2006, 49, 761-770. [CrossRef]

16. Ricco, P.; Baron, A.; Molteni, P. Nature of pressure waves induced by a high-speed train travelling through a tunnel. J. Wind. Eng. Ind. Aerodyn. 2007, 95, 781-808. [CrossRef]

17. Doi, T.; Ogawa, T.; Masubuchi, T.; Kaku, J. Development of an experimental facility for measuring pressure waves generated by high-speed trains. J. Wind. Eng. Ind. Aerodyn. 2010, 98, 55-61. [CrossRef]

18. Heine, D.; Ehrenfried, K. Experimental Study of the Pressure Rise due to Tunnel Entry of a High-Speed Train. In Proceedings of the 18th STAB/DGLR Symposium, Stuttgart, Germany, 1 January 2014.

19. Yang, Q.S.; Song, J.H.; Yang, G.W. A moving model rig with a scale ratio of $1 / 8$ for high speed train aerodynamics. J. Wind. Eng. Ind. Aerodyn. 2016, 152, 50-58. [CrossRef]

20. Zhang, L.; Yang, M.Z.; Niu, J.Q.; Liang, X.F.; Zhang, J. Moving model tests on transient pressure and micro-pressure wave distribution induced by train passing through tunnel. J. Wind. Eng. Ind. Aerodyn. 2019, 191, 1-21. [CrossRef]

21. Ogawa, T.; Fujii, K. Numerical investigation of three-dimensional compressible flows induced by a train moving into a tunnel. Comput. Fluids. 1997, 26, 565-585. [CrossRef]

22. Kwon, H.B.; Kim, T.Y.; Lee, D.H.; Kim, M.S. Numerical simulation of unsteady compressible flows induced by a high-speed train passing through a tunnel. Proc. Inst. Mech. Eng. Part F J. Rail Rapid Transit 2003, 217, 111-124. [CrossRef]

23. Li, X.H.; Deng, J.; Chen, D.W.; Xie, F.F.; Zheng, Y. Unsteady simulation for a high-speed train entering a tunnel. J. Zhejiang Univ. Sci. A. 2011, 12, 957-963. [CrossRef]

24. Uystepruyst, D.; William-Louis, M.; Monnoyer, F. 3D numerical design of tunnel hood. Tunn. Undergr. Space Technol. 2013, 38, 517-525. [CrossRef]

25. Chu, C.R.; Chien, S.Y.; Wang, C.Y.; Wu, T.R. Numerical simulation of two trains intersecting in a tunnel. Tunn. Undergr. Space Technol. 2014, 42, 161-174. [CrossRef]

26. Rabani, M.; Faghih, A.K. Numerical analysis of airflow around a passenger train entering the tunnel. Tunn. Undergr. Space Technol. 2015, 45, 203-213. [CrossRef]

27. Liu, T.H.; Chen, Z.W.; Chen, X.D.; Xie, T.Z.; Zhang, J. Transient loads and their influence on the dynamic responses of trains in a tunnel. Tunn. Undergr. Space Technol. 2017, 66, 121-133. [CrossRef]

28. Zhou, X.S.; Liu, T.H.; Chen, Z.W.; Zou, X.; Liu, D.R. Effect of ambient wind on pressure wave generated by high-speed train entering a tunnel. J. Cent. South Univ. 2017, 24, 1465-1475. [CrossRef]

29. Li, W.H.; Liu, T.H.; Pedro, M.V.; Chen, Z.W.; Guo, Z.J.; Li, M.; Xia, Y.T.; Liu, H.K. Aerodynamic effects of a high-speed train travelling through adjoining \& separated tunnels. Tunn. Undergr. Space Technol. 2021, 113, 103973.

30. Yang, W.C.; Deng, E.; Lei, M.F.; Zhang, P.P.; Yin, R.S. Flow structure and aerodynamic behavior evolution during train entering tunnel with entrance in crosswind. J. Wind. Eng. Ind. Aerodyn. 2018, 175, 229-243. [CrossRef]

31. Li, W.H.; Liu, T.H.; Chen, Z.W.; Guo, Z.J.; Huo, X.S. Comparative study on the unsteady slipstream induced by a single train and two trains passing each other in a tunnel. J. Wind. Eng. Ind. Aerodyn. 2020, 198, 104095. [CrossRef]

32. Ferziger, J.; Peric, M. Computational Method for Fluid Dynamics, 3rd ed.; Springer: Berlin/Heidelberg, Germany, 2002.

33. Huang, Y.D.; Gong, X.L.; Peng, Y.J.; Kim, C.N. Effects of the solid curtains on natural ventilation performance in a subway tunnel. Tunn. Undergr. Space Technol. 2013, 38, 526-533. [CrossRef] 
34. Chen, W.L.; Li, H.; Hu, H. An experimental study on the unsteady vortices and turbulent flow structures around twin-box-girder bridge deck models with different gap ratios. J. Wind. Eng. Ind. Aerodyn. 2014, 132, 27-36. [CrossRef]

35. Li, H.; Chen, W.L.; Xu, F.; Li, F.C.; Ou, J.P. A numerical and experimental hybrid approach for the investigation of aerodynamic forces on stay cables suffering from rain-wind induced vibration. J. Fluids Struct. 2010, 26, 1195-1215. [CrossRef]

36. Tian, H.Q. Train Aerodynamics; China Railway Publishing House: Beijing, China, 2007. (In Chinese)

37. Chen, W.L.; Zhang, Q.Q.; Li, H.; Hu, H. An experimental investigation on vortex induced vibration of a flexible inclined cable under a shear flow. J. Fluids Struct. 2015, 54, 297-311. [CrossRef]

38. Chen, W.L.; Xin, D.B.; Xu, F.; Li, H.; Ou, J.P.; Hu, H. Suppression of vortex-induced vibration of a circular cylinder using suction-based flow control. J. Fluids Struct. 2013, 42, 25-39. [CrossRef]

39. Huang, Y.D.; Hong, T.H.; Kim, C.N. A numerical simulation of train-induced unsteady airflow in a tunnel of Seoul subway. J. Mech. Sci. Technol. 2012, 26, 785-792. [CrossRef]

40. Chen, W.L.; Li, H.; Hu, H. Flow around a circular cylinder with slit. Exp. Therm. Fluid Sc. 2017, 82, $287-301$.

41. Laima, S.; Li, H.; Chen, W.; Li, F. Investigation and control of vortex-induced vibration of twin box girders. J. Fluids Struct. 2013, 39, 205-221. [CrossRef]

42. Chen, W.L.; Gao, D.L.; Li, H.; Hu, H. Passive jet control of flow around a circular cylinder. Exp. Fluids. 2015, 56, 1-15. [CrossRef]

43. Xu, F.; Chen, W.L.; Xiao, Y.Q.; Li, H.; Ou, J.P. Numerical study on the suppression of the vortex-induced vibration of an elastically mounted cylinder by a traveling wave wall. J. Fluid Struct. 2014, 44, 145-165. [CrossRef]

44. Kim, J.Y.; Kim, K.Y. Experimental and numerical analyses of train-induced unsteady tunnel flow in subway. Tunn. Undergr. Space Technol. 2007, 22, 166-172. [CrossRef]

45. Liu, M.Z.; Zhu, C.G.; Cui, T.; Zhang, H.; Zheng, W.D.; You, S.J. An alternative algorithm of tunnel piston effect by replacing three-dimensional model with two-dimensional model. Build Environ. 2018, 128, 55-67. [CrossRef]

46. Izadi, T.; Mehrabian, M.A.; Abouali, O.; Ahmadi, G. 3-D numerical analysis of train-induced flow inside four ventilated underground subway stations connecting tunnels. J. Wind. Eng. Ind. Aerodyn. 2019, 193, 103974. [CrossRef]

47. Liu, F.; Yao, S.; Liu, T.H.; Zhang, J. Analysis on aerodynamic pressure of tunnel wall of high-speed railways by full-scale train test. J. Zhejiang Univ. 2016, 50, 2018-2024. (In Chinese)

48. Ji, P.; Wang, T.; Wu, F. Calculation grid and turbulence model for numerical simulating pressure fluctuations in high-speed train tunnel. J. Cent. South Univ. 2019, 26, 2870-2877. [CrossRef]

49. Ray, W.C.; Joseph, P. Dynamics of Structures, 2nd ed.; McGraw-Hill: New York, NY, USA, 1993. 